\title{
INTERNATIONAL STUDENTS IN CANADA: POLICIES AND PRACTICES FOR SOCIAL INCLUSION
}

\author{
by \\ Courtney Rae Cox, PBD, Simon Fraser University, 2012; BA, Simon Fraser University, \\ 2008 \\ A Major Research Paper \\ presented to Ryerson University \\ in partial fulfillment of the requirements for the degree of \\ Master of Arts \\ In the Program of \\ Immigration and Settlement Studies
}

Toronto, Ontario, Canada, 2014

(C) Courtney Rae Cox, 2014 
AUTHOR'S DECLARATION FOR ELECTRONIC SUBMISSION OF A MRP

I hereby declare that I am the sole author of this MRP. This is a true copy of the MRP, including any required final revisions, as accepted by my examiners.

I authorize Ryerson University to lend this MRP to other institutions or individuals for the purpose of scholarly research.

I further authorize Ryerson University to reproduce this MRP by photocopying or by other means, in total or in part, at the request of other institutions or individuals for the purpose of scholarly research.

I understand that my MRP may be made electronically available to the public. 


\title{
INTERNATIONAL STUDENTS IN CANADA: POLICIES AND PRACTICES FOR SOCIAL INCLUSION
}

\author{
(C) Courtney Rae Cox 2014
}

\section{Master of Arts Immigration and Settlement Studies Ryerson University}

\begin{abstract}
Despite federal policy changes facilitating the recruitment and retention of international students in Canada, programming at Canadian universities is uneven and has created conditions for the population's social exclusion. Canadian immigration policy has positioned international students as a desirable cohort of prospective immigrants, due to their age, economic potential, education, and official language skills. Canada's 2014 International Education Strategy aims to double the number of international students, retaining them as economic migrants, and later permanent residents. However, temporary legal status and limited access to federally funded settlement services positions post-secondary institutions as the population's primary settlement service provider, compounding the barriers to successful societal integration. As such, international graduates face barriers that mirror those of traditional immigrants. Critically exploring Canadian policy and post-secondary programming relating to international students, this paper applies the social inclusion perspective to recommend policy modifications and service approaches to ensure greater inclusion of international students.

Key words: higher education, university, international student, social inclusion, immigration policy, Citizenship and Immigration Canada (CIC), labour market, social capital
\end{abstract}




\section{Table of Contents}

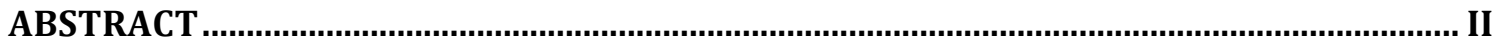

INTRODUCTION SETTING THE STAGE FOR SOCIAL INCLUSION: INTERNATIONAL

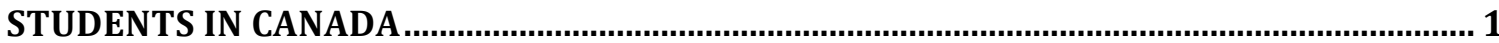

SECTION I THE POLITICAL TERRAIN: POLICIES AND PROGRAMS FACILITATING THE RISE OF INTERNATIONAL STUDENTS IN CANADA

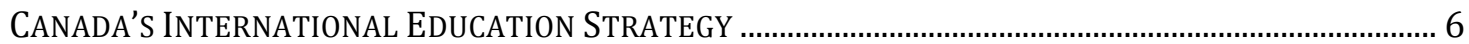

CITIZENSHIP AND IMMIGRATION CANADA PROGRAMS............................................................................ 8

CANADIAN FEDERALISM AND POST-SECONDARY EDUCATION …...........................................................13

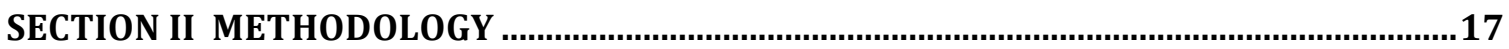

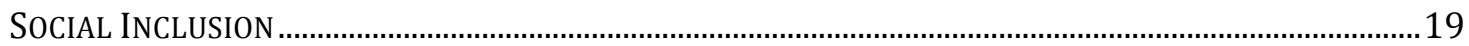

SECTION III LITERATURE REVIEW INVESTIGATING POLICIES, PROGRAMS \&

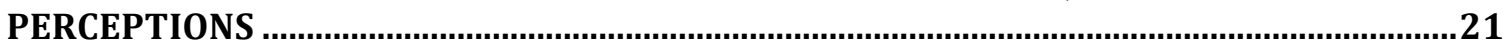

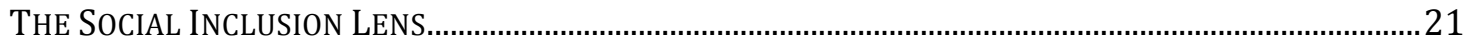

THE LITERATURE

INTERNATIONAL STUDENTS AND CANADIAN HIGHER EDUCATION …....................................................... 24

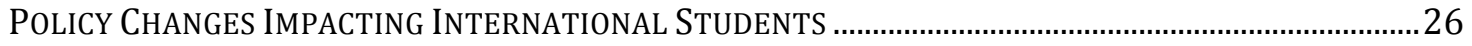

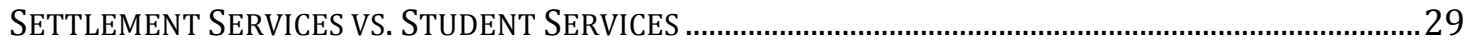

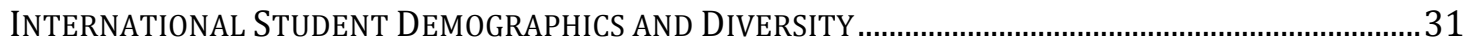

INTERNATIONAL STUDENT SUPPORT: LANGUAGE, ACADEMIC, AND CULTURAL BARRIERS ....................34

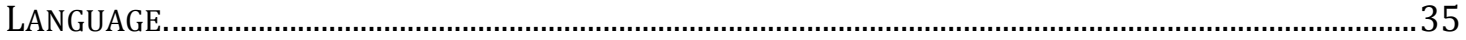

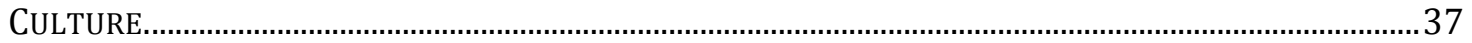

INTERNATIONAL STUDENT SUPPORT: FINANCES, EMPLOYMENT AND THE LABOUR MARKET ..............39

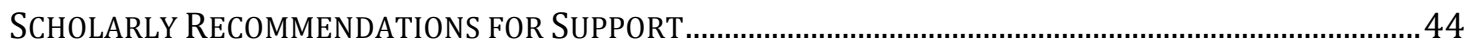

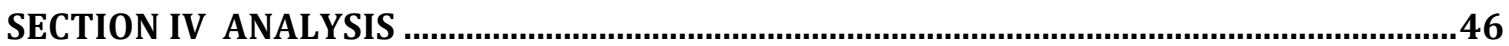

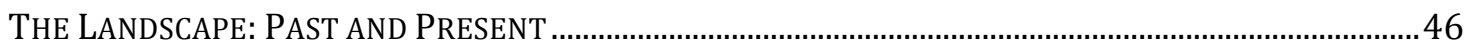

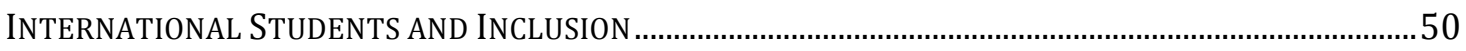

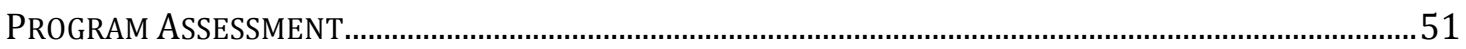

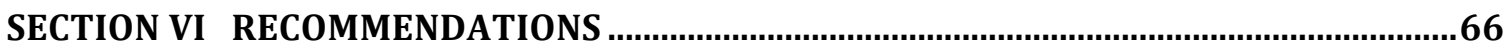

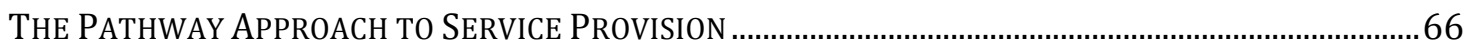

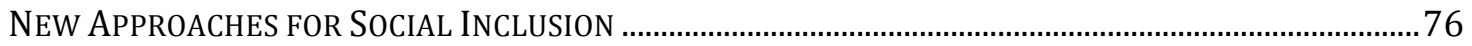

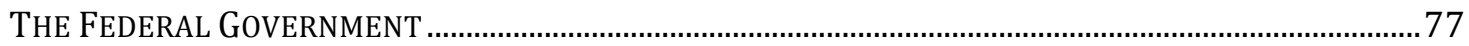

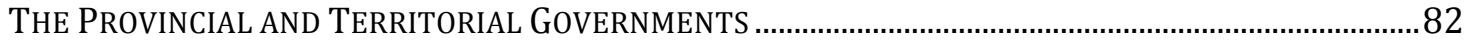

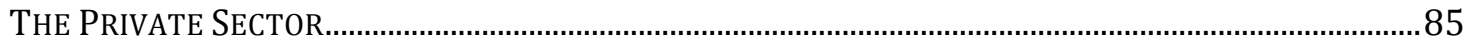

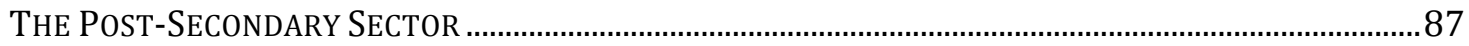

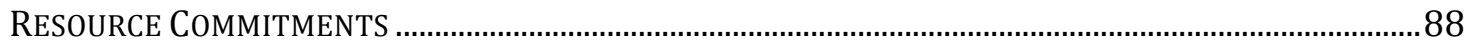

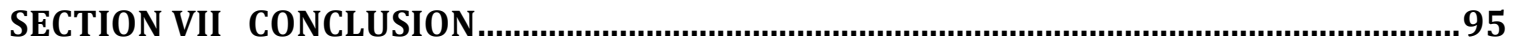

APPENDIX

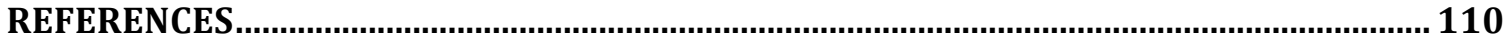




\section{List of Tables and Figures}

Table 1: Evolution of Changes to Canadian Policies and Programs Relating to INTERNATIONAL STUDENTS ……………………………………………………......10

TABLE 2: SCAN OF INTERNATIONAL STUdENT SERVICES IN CANADA ...............................................52

TABle 3: Policy ReCOMmENDATIONS For STAKEHOLdERS OF INTERNATIONAL EdUCATION...... 84

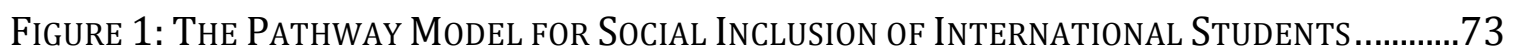




\section{List of Appendices}

APPENDIX: Program Scan of InTERnATIONAL STUDENT SERVICES ................................. 99 


\section{Introduction}

\section{Setting the Stage for Social Inclusion: International Students in Canada}

International postsecondary students in Canada are a diverse population. Coming from 152 countries and speaking over 100 languages (CIC, 2013a), the landscape of Canada's universities are becoming as multicultural as its major cities. The growing diversity on campuses coast-to-coast is a product of Canada's immigration framework, within which the International Student Program has become an integral piece. In January 2014, the federal government in collaboration with the Department of Foreign Affairs, Trade and Development Canada (DFATD), announced that Canada's Economic Action Plan and the new Global Markets Action Plan, would refocus Canada's International Education Strategy to substantially increase the number of international students; a target set to reach 450,000 by 2022 (Govt. Canada, 2014a). The new quota represents another economically driven immigration scheme to bolster the Canadian economy via foreign labour, offering skilled economic migrants pathways to permanent residency in a two-step immigration process (see Section I) (Gates-Gasse, 2010).

A neo-liberal agenda (see below) comprised of dual processes of state and economic reorganization, has influenced the Canadian immigration system since the 1990s (Arat-Koc, 1999; Bauder, 2008). Neo-liberalism has significantly changed the characteristics of prospective immigrants to Canada due to immigration programs that favour individuals who bring with them language, financial, and labour market 
capital. The 2002 Immigration and Refugee Protection Act (IRPA) officially shifted the once humanitarian and family reunification focused system, to an economically oriented framework, ensuring that future immigrants to Canada would be financially self-sufficient. Immigrants whose long-term role in the Canadian economy was uncertain would be admitted with temporary status (Kelley \& Trebilcock, 2010). At an elementary level, neoliberalism describes a change in relationships between society and the state. It is a policy movement that shifts away from post-war conceptions of the state as guarantor of societal well-being, toward a market-oriented system, where individual self-reliance replaces state provisions ensuring human welfare (Arat-Koc, 1999). In relation to migrants, neo-liberalism "reflect[s] increased expectations from immigrants and a lesser commitment from the Canadian welfare state for the rights and welfare of immigrants" (Arat-Koc, 1999, p. 32). In the years following the IRPA, neo-liberalism has continued to guide reforms, transforming the demographics of Canada's potential immigrants, the conditions under which they would enter, and the support available to settle in Canada.

Alongside the neo-liberal ideology guiding Canada's immigration system, a new phase of globalization has emerged. Information and communication technologies have transformed industrial societies into knowledge societies, reorganizing economies globally, and placing increased importance on highly skilled professions requiring advanced training or post-secondary education (PSE) (Guruz, 2011). In newly industrialized countries democratization, privatization rather than central planning, research and development, and decreased regulation for economic 
activity have set the stage for a two fold process resulting in almost 150 million knowledge seekers in the global international education market (Guruz, 2011). Thus, as the economies of East Asia and South America began to quickly industrialize and participate in the global knowledge economy, post-industrial states, including Canada, internationalized their higher education systems, recruiting large numbers of international students. Responding to growing populations of international students and new competitors in the global knowledge economy, neo-liberal, post-industrialized countries began their "race for talent" (Shachar, 2006, p. 110). Seeking to retain international students with locally acquired education to drive national innovation, remain internationally competitive, and supplement declining populations, Canada and other suppliers of international higher education reconfigured immigration policies to retain educational sojourners as skilled immigrants.

Despite immigration reforms to promote the mobility of international students to Canada, the country holds a much smaller share of the global total of mobile students compared to countries with similarly aligned international education strategies. In 2012 the United States, United Kingdom, and Australia, and all attracted at least 100 percent more international students than Canada, ranking Canada in eighth place in terms of share of the global international student market (Simon, 2014). The response to the comparative under-use of Canada's higher education system by international students unfolded as an enhanced International Education Strategy. A key objective of the strategy is to increase international student populations in Canada by 100 percent in less than a decade. According to 
the Strategy, Canada's enlarged global share of international students will create new jobs for Canadians and bolster the national economy through increased international student expenditures (Govt. Canada, 2014a). The population's expenditures on accommodation, tuition, and transportation in the Canadian economy presently amount to approximately $\$ 7.7$ billion annually (Roslyn Kunin \& Associates Inc., 2012). This figure is estimated to reach over $\$ 16$ billion by 2022 ; growth of these expenditures alone mark significant gains for the Canadian economy (Govt. Canada, 2014a).

While the substantial increase of international students in Canada has definite benefits for the Canadian economy, the policy framework leaves unaddressed important consequences of rapidly growing international student populations. Have the conditions of the International Education Strategy, the International Student Program, and the international student-specific pathways to permanent residency taken into consideration the current challenges of Canada's economic immigrants, who like international students are linguistically and culturally diverse? Are postsecondary institutions equipped, in terms of finance, capacity and will, to meet the needs of 100 percent more international students? These are significant questions, the answers to which will ultimately impact the success of the objectives of Canada's policies and programs regarding international students.

While federal policy changes have increased the volume of CIC's International Student Program as a strategy to supplement declining populations and to strengthen the economy through locally educated, skilled labour, few 
provisions have been made to address the conditions of exclusion the policy has created for international student populations. The following sections seek to provide an analytical overview of the policies and practices regarding international students in Canada, as a means to open the dialogue on a new policy-aligned programming agenda for international students, at the heart of which are inclusion and equity. Section I presents the relevant policies and governmental strategies relating to international students and offers a framework to build an argument for the social inclusion of international students in Canada. Section II, provides an explanation of the methodological approach taken in the literature review, analysis and recommendations sections of this paper. Using a social inclusion perspective, methodology establishes the criteria for assessment as well as the context for recommendations. Section III will present current, relevant literature on international students' needs, barriers, and available services, seeking to understand the most important areas of support for international students, and how such needs are being addressed at present. Section IV will analyze the policy and literature findings, supplemented by information obtained from university websites on international student programming. An exploration of needs and programming possibilities will be carried out, guided by federal policy objectives and the creation of conditions for social inclusion. Section V will offer recommendations to facilitate the social inclusion of international students in both policy and practice. It will identify the necessary components of a pathway model for international service provision, which is dependent upon a set of recommendations for governments, universities, and the private sector. 


\section{Section I}

\section{The Political Terrain: Policies and Programs Facilitating the Rise of International Students in Canada}

\section{Canada's International Education Strategy}

Early in 2014, the Canadian federal government, in collaboration with the Department of Foreign Affairs, Trade and Development Canada (DFATD), announced that international education would become a priority sector under the Global Markets Action Plan (Govt. Canada, 2014a). The resulting International Strategy describes four key initiatives (see below) to capitalize on the increasing global demand for international education.

First, the Strategy seeks to enhance Canada's competitive standing in international education by prioritizing goal setting and benchmarking national targets. Carried out by an advisory panel comprised of key actors in post-secondary institutions in Canada, reporting to the Ministers of Finance and Trade, coordinated efforts to attract more international students in a regulated and growth-oriented fashion take precedence under the Strategy. This further aligns international education with national economic growth through the creation of new jobs, increased international student spending, and relieved demographic and labour market pressures, thereby facilitating economic growth nation-wide (Govt. Canada,

2014a). The Strategy's second initiative targets developing and emerging markets as consumers of Canadian education, with plans to improve the branding of national higher education to resonate with target markets, specifically: Brazil, China, India, 
Mexico, the Middle East, North Africa and Vietnam. Expansion and strengthening of relationships with countries and institutions will facilitate the international movement of researchers and students and provide opportunities for joint curriculum creation projects and skills-development programs, leveraging Canada's trade and investment objectives. These collaborative efforts will include (Govt. Canada, 2014a):

- $\$ 42$ million in funding for Citizenship and Immigration Canada to augment the processing of permit and visa applications, facilitating the mobility of international students

- $\quad \$ 13$ million to support Mitacs Globalink Program to attract the best and brightest students and researchers to Canadian universities.

- Increased resources are to be channeled toward scholarships and bursaries for international students.

While the federal funding commitment for international scholarships is undisclosed, the Strategy noted it will exceed the 2013-14 value which amounted to more than $\$ 13$ million; a figure which is complimented by over $\$ 10$ million in doctoral and post-doctoral awards, such as Vanier Canada Graduate Scholarship and Banting Postdoctoral Fellowships Next, activities of the Government of Canada, the provinces and territories, as well as stakeholders in the international education community in Canada are to be aligned to increase the effectivity of the Strategies objectives. This pan-Canadian system of partnerships is to be achieved through roundtables, the Advisory council, the inclusion of the Canadian Consortium on 
International Education, and streamlining efforts with DFATD, CIC, and other agencies and departments with economic interests in internationalizing Canadian education (Govt. Canada, 2014a).

The Strategy's final objective, building on benchmarking, outlines a detailed performance measurement system, to be implemented by establishing specific goals, including (Govt. Canada, 2014a):

- Doubling the number of international in students in Canada by 2022;

- Increasing the number of international students who seek permanent residency in Canada after graduation;

- Regular revaluation of country-specific strategies to mirror the Global Markets Action Plan, specifically regarding the allocation of resources to priority markets;

- Strengthening of support for international students;

- Promotion of two-way student exchanges to highlight the importance of student mobility in the Canadian model of education.

\section{Citizenship and Immigration Canada Programs}

Policies and programs relating to international students, such as the International Education Strategy, have evolved significantly in the 12 years since the implementation of the Immigration and Refugee Protection Act (IRPA). A cumulative snapshot of the changes described in this section can be found in Table 1 below.

The International Student Program. The 2002 regulatory framework 
modified the existing International Student Program (ISP), and set out eligibility for study in Canada with or without a permit, employment regulations, and established a legal description of 'studies' in ways that the Immigration Act of 1976 did not (CIC, 2010). The evolution of the ISP under the IRPA has been drastic. Initially, only one key change was made to the program - international students enrolling in programs six months or less would no longer require a study permit (CIC, 2010). However, by early 2005 the speed of ISP changes increased, beginning with the streamlining of the study permit process, enabling students to transfer between programs of study and institutions before having applied to CIC (CIC, 2010).

Employment programs. Later in 2005, the Post-Graduation Work Permit Program (PGWPP) was implemented, allowing international students the opportunity to apply for a work permit after graduation, for the length of the student's program of study, to a maximum of two years. As outlined in Table 1, students applying under the PGWPP were required to have graduated from a designated institution outside of Vancouver, Toronto, or Montreal, and have a job offer within an approved job "family" under the National Occupation Classification system (CIC, 2010). The geographical restrictions on the PGWPP were lifted in 2008, along with the limitation on the type of employment and the requirement for a job offer. At the same time the permit duration was extended from two-years to three (CIC, 2010). 


\begin{tabular}{|c|c|c|}
\hline POLICY/PROGRAM & YEAR & CHANGES \\
\hline $\begin{array}{l}\text { Provincial Nominee Program } \\
\text { (PNP) }\end{array}$ & $\begin{array}{l}1999- \\
2009\end{array}$ & $\begin{array}{l}\text { Canadian provinces (P) (excluding QC) and territories (T) } \\
\text { (excluding Nunavut) sign and implement agreements with } \\
\text { CIC. PTs department/ministry of } \\
\text { labour/education/immigration manages PNP and sets } \\
\text { program streams for applications based on jurisdictional } \\
\text { economic/labour needs. Successful nominations by PTs } \\
\text { allow candidates to apply to CIC for permanent residency }\end{array}$ \\
\hline $\begin{array}{l}\text { Immigration and Refugee } \\
\text { Protection Act (IRPA) }\end{array}$ & 2002 & $\begin{array}{l}\text { International students are eligible to enroll in } \\
\text { courses/programs } 6 \text { months or less without a study permit }\end{array}$ \\
\hline $\begin{array}{l}\text { Streamlined Application Process } \\
\text { for International Students }\end{array}$ & 2005 & $\begin{array}{l}\text { International students can be granted study permits for the } \\
\text { length of their program of study. Post-secondary students } \\
\text { are able to transfer between programs/institutions } \\
\text { without re-applying for a study permit }\end{array}$ \\
\hline $\begin{array}{l}\text { Post-Graduation Work Permit } \\
\text { Program (PGWPP) }\end{array}$ & 2005 & $\begin{array}{l}\text { International graduates from designated institutions } \\
\text { outside of Montreal, Toronto and Vancouver can apply to } \\
\text { work post-graduation, for a maximum of two years. } \\
\text { Applicants are required to have a job offer within select job } \\
\text { "families" under the National Occupation Classification }\end{array}$ \\
\hline $\begin{array}{l}\text { Off-Campus Work Permit } \\
\text { Program (OCWPP) }\end{array}$ & 2006 & $\begin{array}{l}\text { International students enrolled in a full-time program at } \\
\text { designated institutions may apply for a work permit, } \\
\text { allowing employment for a maximum of } 20 \text { hours per week }\end{array}$ \\
\hline PGWPP & $\begin{array}{l}\text { April, } \\
2008\end{array}$ & $\begin{array}{l}\text { International graduates from a designated institution from } \\
\text { any region in Canada can apply for an open work permit } \\
\text { under the PGWPP, to a maximum of three years }\end{array}$ \\
\hline Online Applications & $\begin{array}{l}\text { Sept., } \\
2008\end{array}$ & $\begin{array}{l}\text { International students in Canada applying for an off- } \\
\text { campus work permit can do so online }\end{array}$ \\
\hline Canadian Experience Class (CEC) & $\begin{array}{l}\text { Sept., } \\
2008\end{array}$ & $\begin{array}{l}\text { Establishment of new immigration stream focusing on } \\
\text { professional, managerial and skilled work experience in } \\
\text { Canada. Under the CEC international graduates' work } \\
\text { experience and a Canadian education }\end{array}$ \\
\hline International Education Strategy & $\begin{array}{l}\text { Jan., } \\
2014\end{array}$ & $\begin{array}{l}\text { Federal government launches new, comprehensive } \\
\text { international education strategy for Canada, focusing on } \\
\text { branding/marketing Canadian education internationally, } \\
\text { targeting priority markets for educational partnerships, } \\
\text { increasing international students in Canada by } 100 \% \text { by } \\
2022 \text {, and generating growth in all regions of Canada }\end{array}$ \\
\hline CEC & $\begin{array}{l}\text { May, } \\
2014\end{array}$ & $\begin{array}{l}\text { A cap of } 8000 \text { new CEC applications, and sub-caps of } 200 \\
\text { for each NOC B applications established, preparing for the } \\
2015 \text { launch of a new immigration stream Express Entry. } \\
\text { Work experience in several food service and } \\
\text { administrative positions under NOC B no longer accepted } \\
\text { in the CEC. }\end{array}$ \\
\hline $\begin{array}{l}\text { International Student Program } \\
\text { (ISP) }\end{array}$ & $\begin{array}{l}\text { June, } \\
2014\end{array}$ & $\begin{array}{l}\text { New rules to the ISP implement standards for learning } \\
\text { institutions to become designated and able accept } \\
\text { international students, require immigrants on study } \\
\text { permits to actively pursue studies while in Canada, and } \\
\text { allow international students studying at designated } \\
\text { institutions/programs to work part-time, off campus, and } \\
\text { full time during school breaks without a work permit. }\end{array}$ \\
\hline
\end{tabular}

Table 1: Evolution of Changes to Canadian Policies and Programs Relating to International Students

Note: Adapted from "Evaluation of the International Student Program". Evaluation Division, Citizenship and Immigration Canada, 2010. 
The ability of international students to gain employment during study in Canada has also changed considerably since the introduction of the IRPA. Only with the 2006 introduction of the Off-Campus Work Permit Program (OCWPP) were international students studying at designated institutions legally able to work offcampus, up to 20 hours per week (CIC, 2010). Such employment related changes to the International Student Program marked a critical policy shift, positioning international students as economic immigrants.

Pathways to permanency. By September 2008 CIC had implemented a new pathway to permanent residency, the Canadian Experience Class (CEC); the criteria for which specifically targeted international graduates as applicants. International graduates with professional, managerial, and skilled work experience in Canada, typically gained via the PGWPP, and a Canadian postsecondary education, became eligible to apply for permanent residency in Canada under the new Canadian Experience Class (CIC, 2010).

The Provincial Nominee Programs (PNP) represent another change in the policy landscape affecting international students, and at the time of implementation, marked a shift in the once solely federal jurisdiction of immigration policy, complimenting Federal-Provincial/Territorial Agreements. Since the mid-1990s the PNP has offered skilled immigrants the opportunity to apply for nomination for permanent residency by a specific province or territory (PT), based on regional economic needs, as defined by PTs themselves (CIC, 2013). Over the past decade, due to the alignment of selection criteria with immigrant skills and regional labour needs, these programs have received increased attention by federal and provincial 
governments as well as from immigrants. Applicants first request nomination by a specific province or territory, and then apply to CIC to become a permanent resident (CIC, 2013b).

Recent changes to the International Student Program. As Table 1 exemplifies, the International Student Program has experienced significant changes since the implementation of the IRPA. The changes described have facilitated international students' transition to the Canadian workforce, and later to permanent residency. In 2014, in the spirit of continued liberalization of economic opportunities for international students, CIC announced that students holding a study permit would no longer be required to apply separately for a work permit. As of June 2014, part-time, off campus work privileges are included in the conditions of study permits. New rules to address potential misuse or abuse of the International Student Program were also implemented in the June 2014 changes and include requirements for individuals holding study permits to actively pursue education while in Canada. Additionally, a more rigorous system of standards for educational institutions to become legally designated to accept international students holding study permits was established (Govt. Canada, 2014b).

The totality of changes to the International Student Program and the associated criteria changes for permanent residency pathways have positioned international students as one of the most economically important immigrant populations to federal and provincial governments. The intended outcomes, as expressed in Canada's International Education Strategy (Govt. Canada, 2014a), are to continue the recruitment and retention of international students. Based on 
international graduates' education, language skills, and work experience in Canada, it is expected the group will smoothly transition into productive labour for the Canadian economy.

\section{Canadian Federalism and Post-Secondary Education}

Discussions of the Canadian policy climate in the context of education cannot be understood without addressing the structural nuances of federalism in Canada. Bakvis and Skogstad's (2008) work provides a foundation for the understanding of federalism, in the Canadian context:

The foremost principle of federalism is that each order of government is autonomous within its sphere of authority; its jurisdictional powers may be altered only in conformity with constitutional provisions, never through unilateral action by the other government. [...] The second principle of federalism [...] [is] to provide a balance between unity and diversity ( $\mathrm{p}$. $4-5)$.

The authors further explain that performance related issues of federalism, for example the capacity to produce results through negotiation or information exchange, are a result of the relationship between the central government and the constituent units. That is, whether the central government is subordinate to the constituents, or vice versa (Bakvis \& Skogstad, 2008). Unlike most federations, Canada offers its provinces and territories little formal, structured representation at the federal level, which ideally would take the form of a second chamber of Parliament. Aside from the Senate, provincial and territorial underrepresentation at the federal level has created a certain level of regionalism or weak intrastate federalism that segregates the interests of Canada's provinces from wider 
national concentrations. Weak intrastate relationships are highly problematic in the context of international education, details of which will be described below.

Education in Canada is exclusively a provincial jurisdiction (Guruz, 2011), and consequently the provinces have direct control of all education sectors and educational levels, developing legislation, and regulating and coordinating primary through post-secondary education (Shanahan \& Jones, 2007). As noted weak intrastate federalism has resulted in the absence of a federal coordinating body for education (Guruz, 2011). In relation to post-secondary education, the constitutional division of powers and regionalism is problematic, as core federal policy arenas intersect with higher education (Shanahan \& Jones, 2007). These include national security, external affairs, economic development, and Indian affairs. While provincial governments provide operating support to the postsecondary institutions in their jurisdictions, federal-provincial transfers represent important financial support to institutions of higher education (Shanahan \& Jones, 2007), despite provincial autonomy in educational administration and governance. Federal funding takes the form of tax point transfers, cash transfers, or equalization payments, representing an important, albeit decreasing source of funding directed toward post-secondary institutions (OECD, 2004).

Since 1997 the federal government has re-envisioned post-secondary institutions as core contributors to national innovation, and has attempted to transform the parameters of funding at higher education institutions (OECD, 2004). Financial transformations have manifested through increased funding of 
research and development, beginning with the 1997 Canada Foundation for Innovation at $\$ 3.15$ billion, and spanning through to the 2000 creation of Canada Research Chairs, at $\$ 900$ million (OECD, 2004). The 2014 announcement of an enhanced federally operated international education strategy marks further progression toward a blended jurisdictional model of higher education.

Despite these gains, core funding for post-secondary institutions by the federal government remains on the downturn, with federal support amounting to 57 percent of overall funding of PSE, down from more than 90 percent in the 1970s (Canadian Federation of Students, 2013). Further problematizing the ineffective federal-provincial post-secondary funding model is the federal positioning of higher education as an economic immigration tool; a point of criticism by PSE administrators, who note the shift as ethically problematic (Gates-Gasse, 2012). The continued reduction of federal funding for PSE has downloaded financial responsibility of operating higher education institutions onto students through user fees, resulting in disproportionate increases in tuition (Canadian Federation of Students, 2013). As federal policy facilitates the entry of diverse student populations with unique service needs onto provincially governed post-secondary campuses, core financial support for provinces' PSE needs must be augmented to meet the long-term federal vision of international students as economic migrants. At present many provinces and universities view the lack of PSE funding, and the continued and rising flows of international students into Canadian universities as an unfair deal. The role of Canadian federalism in the social inclusion of international students on provincial and 
university levels will be analyzed in later sections, and will provide a platform for practical and policy recommendations involving key actors in Canadian international education. 


\section{Section II}

\section{Methodology}

A social inclusion lens guides the research and analysis carried out in this paper. This approach requires comprehensive analysis of issues and/or barriers, and thus draws on an exclusion perspective. The social inclusion lens takes the barriers experienced by the victims of exclusion and considers the policies and institutional processes that create conditions of exclusion. It then assesses institutions, policies, and practices that perpetuate exclusion and recommends solutions that include all actors involved, including the victims themselves. As such, the social inclusion lens is applied throughout the following sections to acknowledge barriers faced by international students, assess current policies, actors, and support mechanisms that either perpetuate exclusion or facilitate inclusion, and thus consider innovative responses to dismantle barriers and achieve equitable outcomes. To that end, it is essential to engage policies, programs, and experiences as interrelated phenomena. Additionally, through the social inclusion lens, policy is seen as a driving factor behind social exclusion and therefore the methodology of this analysis considers achieving policy success a criterion of social inclusion, and policy failure a criterion of social exclusion.

The Citizenship and Immigration Canada (CIC) website and several CIC Evaluation Reports were assessed to understand the International Student Program and the affiliated permanent residency pathways, as a means to contextualize recent policy changes and university programming agendas. Results were obtained using 
keyword searches (e.g. "international student", "International Student Program", "foreign student") on the CIC website; the most useful data was gathered using the 2010 CIC Program Evaluation on the International Student Program.

As a basis for exploration into the social inclusion of international students at Canadian universities, a literature review was undertaken to provide critical insight from a scholarly perspective, to identify gaps in research, and establish common understandings of international students. To support these findings several working papers and informational reports were used. The websites of four publically funded universities in Canada were then reviewed, gathering information regarding specific programs and services offered to international students. Information obtained using keyword search criteria, including "international student", "language", "academic", "culture", "employment" and "finances" were applied to explore key domains of social inclusion present on Canadian campuses. Due to the scope of this project, only four institutions were surveyed. The choice of institutions assessed were based on the author's assumption that due to regionalism in Canada, programming initiatives in different geographic areas of the country would reflect the nuances of the political climate, and highlight a patchwork approach to international student services due to weak intrastate federalism. The comprehensive findings of the universityinternational student service scan can be found in Appendix A and in short-form in Table 2 . The succeeding exploratory analysis will use a social inclusion perspective to evaluate the quality and quantity of targeted programming, and further, will unpack federal policy to explore the ways in which current policies set the conditions for inclusion or exclusion. 


\section{Social Inclusion}

The social inclusion perspective has immense value in application to the affairs of international students in Canada. As temporary migrants, international students are excluded from services and rights granted to those with formal, permanent status, or citizenship. To this end, the social inclusion perspective puts forth the notion of democratic citizenship, whereby members of society possess rights based on their membership to the community rather than formal citizenship (Saloojee, 2003). As Saloojee (2003) explains:

Social inclusion is about social cohesion plus, it is about citizenship plus, it is about the removal of barriers plus, it is anti-essentialist plus, it is about rights and responsibilities plus, it is about accommodation of differences plus, it is about democracy plus, it is about a new way of thinking about the problems of injustice, inequalities and exclusion (p. 14).

Earlier work by Benick and Saloojee (1996) applies inclusivity to education and suggests that an inclusive learning environment is "about respecting students and valuing them as partners" (p. 2). This notion of partnership is crucial in understanding the social inclusion perspective and in differentiating it from frameworks of exclusion. As a guide for the assessment of the policies and practices related to the rise of international students in Canada, social inclusion provides a platform to assess not just policies, programs, or outcomes, but widens the viewpoint to include individuals and communities who influence and are influenced by the aforementioned. This includes international students, community organizations, university staff and faculty, policy makers, the private sector, and society as a whole. Questioning if and how international students are being treated 
as partners in their ascribed hybrid role as students and potential economic contributors the social inclusion lens unpacks the intentions of federal policy relating to international students. Further, it suggests assessment of the quantity and quality of university-level support, and provides a starting point for a dialogue that encourages the alignment of federal policy with attainable, equitable outcomes through the engagement of all invested actors.

The relationship between social inequality and opportunities for success strongly influences social participation, deciding the extent to which individuals are able to access education and training, amongst other factors (Walton, 2000). As an extension and response to social exclusion, the social inclusion perspective finds similar connections. While acknowledging the importance of removing barriers excluding certain populations from equitable educational and essential supports for social and economic success, the perspective also looks at policies and practices of institutions not only as culprits of exclusion but also as sites of progress, capable of deconstructing societal obstacles and leveling the terrain toward inclusion (Saloojee, 2003). This analysis takes the social inclusion perspective to a new level, looking within higher education institutions and exploring the extent to which those already accepted into the formal institutional structure are granted tools and opportunities for success during and after their education experiences. Given the current policy agenda in Canada, this exploration is an important one. 


\section{Section III}

\section{Literature Review Investigating Policies, Programs \& Perceptions}

\section{The Social Inclusion Lens}

International students attending Canadian post-secondary institutions are increasingly diverse. Almost twenty years ago Benick and Saloojee (1996) commented that: "learners attending Ontario colleges and universities are, on virtually any demographic variable (race, gender, ethnicity, social class, religion, language, age, disability), more diverse than any time in the past" (p. 1). Today, this holds true for all regions in Canada. Though the social inclusion lens has yet to be applied to international student populations in scholarly work, its principles are critical in considering educational equity for international student populations. Saloojee (2003), citing Walker and Walker, explains that social exclusion "refers to the dynamic process of being shut out, fully or partially, from any of the social, economic, political or cultural systems which determine the social integration of a person in a society" (p. 2). Given international students' temporary migration status, and combined with the federal expectation that such populations will easily integrate into the Canadian economy, it is important to look at barriers as well as opportunities. The pairing of exclusion and inclusion, through application of the social inclusion perspective, suggests not merely the causes for a potential policy failure, but the actors, actions, and resources necessary to provide the conditions for policy success, considering approaches that facilitate equity, and strive for equality (Ogbuagu \& Ogbuagu, 2013). Inclusion therefore means more than consideration or 
token change (Bishop, 2005). It represents an action-oriented approach that engages all stakeholders, including international students, and strives to combine policy with practice through evaluation and a unified values framework that eliminates discrimination and celebrates difference (Saloojee, 2003; Bishop, 2005).

The findings of this literature review frame the following exploratory analysis, in that it applies a social inclusion lens to a group whose long-term struggles have not yet been experienced. While international students have become a distinct unit of analysis in scholarly literature, many authors acknowledge international student challenges in isolation from each other. Each issue described provides a deeper understanding of language, culture or employment in the international student experience. However, these issues do not exist separately from one another: language proficiency issues impact confidence, which deters students from creating social capital with Canadian students; later this will impact the networks students have to gain career employment, and in turn, influence their final decision to stay in Canada to pursue permanent residency or to return home with their degrees. Thus, the information gathered serves as a platform to engage dialogue on creating a comprehensive international student social inclusion agenda that fuses policy goals with university support programs.

\section{The Literature}

Literature analyzing international students has increased over the past 15 years. It is interdisciplinary and seeks to understand the challenges and opportunities posed by increasing the numbers of international students for governments, 
postsecondary institutions, practitioners, and for the students themselves. Between 2006 and 2008 repositioning of international students in the Canadian immigration system sparked a new wave of literature focusing on the migration intentions of international students and the implications of international students as economic migrants and permanent residents (Gates-Gasse, 2010; Roach, 2011; Gates-Gasse, 2012; Kelly, 2012). This second wave of literature published after 2006 contextualizes more senior studies of international students' language proficiencies, acculturation, economic well-being, and pursuits of permanent status, and highlights the protracted struggles of international students left unresolved by policy makers and practitioners. Alongside the literature on international student barriers have emerged important works on globalization, neo-liberalism, and their impacts on higher education (Shachar, 2006; Zheng, 2010; Guruz, 2011). Assessing international student needs for successful integration and social inclusion, the following literature review will provide perspective on current programming at post-secondary institutions targeted at international populations, as well as situate the Canadian approach to international higher education in a global context.

Major gaps were noted in the literature on the analysis of types of programs available to international students. A survey of 4 major, publicly funded Canadian post-secondary institution websites found that a wider range of programs exist than those described in the literature, and can be found in Section III, Table 2. The exception to this somewhat narrow view of international student needs and programming available was Gates-Gasse's (2012) review, which sought to assess international student support comprehensively and in light of federal policy 
intentions. The content of university websites was not included in this literature review due to the search parameters of peer-reviewed journals, theses and dissertations, published scholarly books and working papers from established organizations in the international education and immigration fields. The rationale for this exclusion was to evaluate the academic perspectives that are established or emerging in the disciplines related to immigration and settlement, and to guide further scholarly work in this capacity.

\section{International Students and Canadian Higher Education}

The global context. The number of international students globally is increasing, and is expected to reach 7.2 million by 2025 (OECD, 2004). Within this growing global sector of international education, Canada has made incremental yet cumulatively significant policy changes in attempts to become an influential actor in the sector. Canada is making progress but it still lags behind competitor countries such as the United Kingdom, United States, and Australia (Guruz, 2011). In recent years explicit policy changes by Canada's federal governments have repositioned international students to occupy economic roles, thereby transforming the national approach to cross-border higher education to "the skilled migration approach" (OECD, 2004, p. 12). Today, international students not only play a central role in universities on a temporary basis - valued for cultural, political, and academic reasons, representing the former "mutual understanding approach" (OECD, 2004, p. 13) but are also conceptualized as a new source of permanent, skilled human capital to contribute to the national economy (OECD, 2004; Arthur \& Flynn, 2011). While 
Canada has been, in some capacity, demographically reliant on immigration for much of its history, only recently has the country deliberately pursued the recruitment and retention of international students from an immigration perspective (Guruz, 2011).

Over the past two decades, socioeconomic developments have created optimal conditions for a global agenda of higher education. Guruz (2011) sees these conditions as consisting of demand increases, demographic shifts, and the rise of non-traditional source countries of immigrants; the impacts of globalization on technology and markets; and, increased international competition. Neo-liberalism, applied here as models of "policy and social regulation that emphasize[s] the ideals of enterprise, skills, autonomy, and flexibility" (Walsh, 2008, p. 796), has played an important role in and has reinforced these shifts.

The role of neo-liberalism. As the federal government's conceptualization of international students has evolved and neo-liberal ideology has permeated Canadian federal policy creation, dramatic changes have taken place in relation to international students' status and privileges while in Canada; all of which promote interaction with the labour market and attribute an assumed level of autonomy to such individuals (Guruz, 2011; Gates Gasse, 2012). As the state's role transformed from provider of resources to manager of the economy, the responsibility for ensuring societal well-being was transferred onto individuals (Arat-Koc, 1999). While federal policy regimes have been reorganized to favour economic selfsufficiency, few tangible opportunities have been provided to encourage or facilitate such behaviours. Growing performance expectations, especially of immigrants, and 
drastically reduced social supports have positioned the Canadian state as distinctly neo-liberal (Arat-Koc, 1999).

\section{Policy Changes Impacting International Students}

Early changes. As outlined in Section I, Table 1, many changes have occurred since the mid-1990s when Provincial Nominee Programs (PNP) were created as a means to entice international graduates to gain employment and settle in areas other than Montreal, Toronto, and Vancouver; regions which historically and presently attract the majority of immigrants (Alboim, 2011). Due to the time international students spend at postsecondary institutions as temporary migrants, it was assumed by governments that the networks created during this time would facilitate labour market integration on a permanent basis. This resulted in a twostep immigration system, culminating in the 2008 addition of a second pathway to permanent status for international students, the Canadian Experience Class (CEC) (Gates-Gasse, 2010).

Employment. Similar changes have taken place in respect to work entitlements for international students during their study period. In the years leading up to the introduction of the CEC, CIC developed the Post-Graduation Work Permit Program as well as the Off-Campus Work Permit Program to allow international graduates to transition easily into the Canadian economy (Fama, 2011). While these changes have received generally positive responses, criticism centers on the unequal investment to benefit ratios between international students and Canadian governments. The argument is based on the economic and societal 
contributions of international students and the lack of policy changes regarding their ability to access government funded settlement services (Alboim. 2011; Fama, 2011; Lowe, 2011; Gates-Gasse, 2012).

Targeting international students as immigrants. To date, the policy changes that have occurred have been driven by increased regulation of the Canadian immigration system, often creating confusing and seemingly unfair conditions for international students to transition into the labour market, and potentially, to permanency (see Section I, Table 1). In the spirit of international education's "race for talent" (Shachar, 2006, p. 105), the PNP and CEC are designed to focus on actual employability rather than prospective employability (Baglay, 2012). Structurally, PNPs have created uncertainty for users of the Canadian immigration system, as each province sets its own selection criteria and entry streams, resulting in a multitude of pathways and programs for two-step immigration, and thereby creating an unequal system for international students based on the province in which they study.

To date, several provinces have created PNP international student streams, which often have more flexible selection criteria than the CEC (Baglay, 2012). Conversely, the CEC has sparked controversy amongst international students and policy commentators, following the November 2013 announcement that as of May 2014 a cap of 8000 was to be placed upon new CEC applications, as well as a sub-cap of 200 on each National Occupation Classification (NOC) B applications (GOVision, 2014). Based on the Canadian government's expression of need for skilled human capital and the development of programs to permanently attract international 
students, the removal of 6 eligible occupations from the CEC is problematic (GOVision, 2014).

Changes to the CEC. While it is too early to fully understand the impacts of these changes on the International Education Strategy's goals and outcomes, the removal of several administrative and food service occupations from the CEC, popular entryways to Canada's competitive labour market, may work against the Strategy's intentions. With the closure of several entry level NOCs, many international students already in Canada who have not yet applied to the CEC, may choose to return to their home countries or continue their migration journey in a third country, due to the inaccessibility to entry level jobs in the Canadian labour market (GOVision, 2014).

Further, the changes mark a lack of transparency in Canada's brand of international education, Imagine Education au/in Canada, which highlights the country's straightforward study-work-permanence transition (CBIE, 2013). This points to the mismatch between neo-liberal market logic and the conditions under which individuals will choose to permanently migrate away from their country of origin (Sweetman \& Warman, 2010). While Sweetman and Warman (2010) wrote at a time prior to the CEC changes, their comment still resonates: "no CEC-stream immigrants have been in the Canadian labour market long enough to enable an evaluation" (p. 61). Thus, it may be noted that there is an element of shortsightedness in the CEC reforms.

International students as ideal immigrants. The CEC caps lead to an important theme within the literature: international students as the "ideal" 
immigrant. This ideal is based on the assumption that the time international students spend in Canada prior to permanent immigration prepares them culturally, linguistically, and socially for Canadian life. Often this group is referred to as "designer immigrants" (Gates-Gasse, 2012, p. 272), a term that pairs their acculturation with the assumption that their Canadian credentials will allow them to integrate easily into the labour market (Peykov, 2004; Gates-Gasse, 2010; GatesGasse, 2012). The construction of an ideal or preferred immigrant is distinctly neoliberal, in that the ideality is self-sufficiency. Self-sufficiency has been an important piece of the immigration discourse throughout Canada's colonial history and it continues to influence policy creation, and ultimately, immigrant selection (Kelley \& Trebilcock, 2010). The rising costs of international education in Canada ultimately reduces participation to those individuals who are not only academically capable of success in Canada, but bring with them financial capital to supplement the economy and ensure economic independence (Zheng, 2010).

\section{Settlement Services vs. Student Services}

The criticism regarding the exclusion of international students from accessing settlement services created for immigrant integration is less about language programs and housing services, and more about labour market readiness programs (Lowe, 2011; Kelly, 2012). Arguing that immigrant groups who do not have access to settlement services experience difficulty integrating in the labour market, Lowe (2011) highlights the necessity to expand the federal settlement service funding model to encourage international students to stay in Canada post-graduation and 
likewise, to fulfill federal policy. This echoes Alboim's (2011) caution that if Canada continues its quest to retain international students as permanent residents, a clear settlement service plan must be developed. As Anisef, Sweet and Adamuti-Trache (2010) note, if the federal government continues to relax entry conditions for linguistically and culturally diverse immigrants, Canada has a responsibility to provide improved settlement services.

The exclusion of international students from accessing federally funded immigrant settlement services is especially salient due to the propensity of this form of funding in immigrant settlement service networks, with federal funds accounting for 80 percent of all settlement funding in Ontario (Lowe, 2011). Because of this service gap universities have taken on the role of immigrant recruiters and settlement service providers, as well as educators (Lowe, 2011; Wade \& Belkhodja, 2011; Gates-Gasse, 2012). Immigrant settlement service providers have expressed interest in partnering with post-secondary institutions to deliver international student support, however CIC funding regulations have prevented such partnerships (Chira, 2009). Additionally, previous devolution of services for permanent immigrants from the public sector to the settlement sector has overburdened the industry and has financially prohibited settlement service providers from widening their scope of cliental without federal support (Evans \& Shields, 2000; Siemiatycki \& Triadfilopoulos, 2010). This creates ethical issues for postsecondary institutions, who as educators accept international students to their campuses on a temporary basis, to receive a Canadian education. However, with the repositioning of international student populations as potential contributors in the 
Canadian economy, there has been a push to include labour market programming in the international student service agenda (Gates-Gasse, 2012).

These conflicting agendas of governments and universities have resulted in a fragmented approach to servicing international student needs, an outcome that if continued would undermine the quality of education this population receives. Postsecondary institutions have been required to develop creative and cost-effective approaches to serve international students. Moving forward, there is an urgent need for common standards and clear definition of expectations and responsibilities of governments and universities (Alboim, 2011). As it stands, both governments and universities feel the other is positioned to gain the most from the presence of international students, leaving the discussion at a standstill (Gates-Gasse, 2012).

\section{International Student Demographics and Diversity}

Diversification and equality. Canada's emergence as an actor in international education was closely followed by a transformation in international student demographics on Canadian campuses, foreshadowing the 2014 International Education Strategy's focus on developing and emerging markets. Between 2000 and 2004 Chinese international students attending Canadian postsecondary institutions increased by 390 percent, thereby becoming the most represented country in this population group (Guruz, 2011). Similarly, the number of international students from India rose exponentially within this period; in 2000 only 860 Indian students were enrolled in Canadian universities - by 2011 Indian 
international students surpassed the number of Korean, Hong Kong Chinese, Japanese and British students at Canadian universities (Guruz, 2011). Meanwhile, students from Asia have steadily risen to account for the largest share of international students; Canada's top three source countries for international students are China, India and Korea, which together account for 49 percent of all international students in Canada (CBIE, 2012). Conversely, students from Africa have steadily declined since 1992 dropping from $17 \%$ of total international students in Canada, to 12\% in 2008 (CIC, 2013a). These trends illustrate how Canada's growing presence in the global knowledge economy has led to demographic diversification at universities Canada-wide. However, such transformations have not occurred with educational equity as a premier consideration, and as a result have excluded academically competitive students from postsecondary study in Canada (Zheng, 2010).

Just as neoliberal globalization failed to make free-trade real and equalize global wealth through technology and flexibility, international higher education has created a greater divergence between the have's and have not's, often establishing hierarchies of nation-states. Those countries that rapidly industrialized and produced a middle class capable of participating in education abroad are thus positioned at the top of such a hierarchy (Zheng, 2010). The rapid industrializationmiddle class phenomenon is represented by countries such as China, India, and Korea, not surprisingly overrepresented in international student populations at Canadian PSEs. Likewise, those nation states that have not been able to 'catch up' industrially are in turn underrepresented in international student populations in 
Canada, reflecting the persevering rich-poor dichotomy in many countries in Latin America and Africa.

Homogenizing international students. Despite restrictive financial constraints acting as barriers to accessing the Canadian postsecondary system, substantial diversity amongst international student populations exists. This diversity is a matter not well understood by university student administrators. Keynon et al (2012) study at the University of British Columbia found that international student populations are not homogenous, despite the umbrella term 'international student'. While all students, domestic or international, experience processes of acculturation and integration upon beginning postsecondary studies, these matters are distinct and require targeted support. Clearly illustrating this diversity, Keynon et al (2012) present the contrast of acculturation barriers between American and Indian international students. Their commentary notes the need to customize outreach and programming agendas to recognize group-specific challenges, often misunderstood by the administrative amalgamation of international student bodies.

Because Canadian post-secondary institutions do not collect data on the race, ethnicity, or religion of students there is a dearth of knowledge on how the diversity of students interacts with success achieved. Therefore, Canadian universities and colleges have relied on student activist movements to instigate program development that supports diverse backgrounds. Instances of this type of programorigin are exemplified well in the Lesbian Gay Bisexual Transgender Queer (LGBTQ) movement at the University of Toronto or the Black student movement at Dalhousie 
University, both of which pushed university administration to include the unique service and pedagogical needs of their respective populations into the policies and practices on campus (McGrath, 2010). Student-led rights campaigns, most powerful during the 1960s and 1970s, have set the stage for diversity movements on university campuses today; however, success of this type of program initiation relies on the security felt by students to openly display their difference. This is problematic when factors such as culture and sexual orientation, or health, or success intersect; for many international students cultural perceptions of such matters differ greatly from Canada (McGrath, 2010; Mirwaldt, 2010). McGrath (2010) calls for "a shift from student organization-based activism to institutionalbased advocacy " (p. 160), with the onus on the university community as a whole to ensure diversity and inclusion practices are in place.

\section{International Student Support: Language, Academic, and Cultural Barriers}

Universities have sought to develop specialized programming to respond to the barriers preventing full and equitable inclusion of international students, in academic, language and cultural domains. This service responsibility rests almost entirely on educational institutions due to international students' temporary status, and their ineligibility to access traditional immigrant settlement services that work to alleviate the hardships of settling in a new country (Roach, 2011). As Albiom (2011) notes, this is problematic because of the lack of legislated standards for educational institutions to provide international student services, resulting in differences in the quality support offered by universities, and in turn, the quality of 
education received.

Several authors have identified approaches to international student programs, and analyzed their outcomes, either comprehensively (Snow-Andrade, 2006; Kamara \& Gambold, 2011; Gates-Gasse, 2012) or in terms of the needs programs seek to address (Arthur \& Achenbach, 2002; Cheng et al, 2004; Popadiuk \& Arthur, 2004; Guo \& Chase, 2011; Liu, 2011; Ranta \& Meckleborg, 2012). These scholarly assessments have found that despite the prevalence of international student specific programming at many universities, significant barriers have yet to be dismantled. These include English language proficiency (Liu, 2011; Gates-Gasse, 2012; Ranta \& Meckleborg, 2013), cultural adjustment (Myles \& Cheng, 2003; SnowAndrade, 2006), and academic acculturation (Cheng \& Fox, 2008; Guo \& Chase, 2011).

\section{Language.}

Proficiency. English proficiency test scores have become an important focus for admissions committees in many Western universities, a reaction to claims that NNES international students are reducing the quality and value of higher education (Benzie, 2010). In fact, such claims played a part in the reconfiguration of the Australian International Student Program (Hawthorne, 2011). Higher English proficiency levels have been found to have positive effects on international students perceptions of security and well-being (Sawir et al, 2012), their ability to form bonds with students other than co-nationals or fellow international students (Hendrickson et al, 2011), and their academic success (Daller \& Phelan, 2013). 
Interestingly, while most NNES international students struggle with language skills, their GPAs are often comparable to domestic, native speakers (Berman \& Cheng, 2001), pointing to the impacts proficiency has beyond the classroom.

Naturalistic language acquisition. Learning the national language in a student's country of study emerges in the literature as a pull factor for many international students' migration journey (Liu, 2011; Ranta \& Meckleborg, 2103). Ranta and Meckleborg (2013) based a longitudinal study of Chinese international students exposure to English and change in proficiency levels. The study was based on the belief held by many researchers and educators, as well as international students themselves, that everyday exposure to language and contact with native speakers leads to proficiency. The authors claim this to be untrue. Alternatively, they found that post-secondary NNES international students continued reliance on co-ethnic social networks, first language media and entertainment, and faculty relationships with co-ethnics, often results in little progression in English proficiency levels (Ranta \& Meckelborg, 2013). In a similar vein, Liu (2011) writing as a former international student notes that upon arrival in Canada, from her native China, she felt her English proficiency levels were not adequate for full participation in Canadian academic or social life. She highlights the variance between English Proficiency scores required to gain admission, and actual proficiency required for inclusion.

English for academic purposes. Degree credit, academic language courses are suggested as a practical option to address the busy schedules and the language barriers faced by international students. Cheng et al (2004) find targeted academic 
language support to be a worthwhile solution and suggest programs that focus on presentation strategies, lessons on colloquialisms, and note-taking practice in English; all transferable skills to course work, integration, and employment. While the authors make important points about the necessity of language learning tailored to NNES reliance on translation for academic work, practicality is not integrated into their recommendations. How post-secondary institutions would implement mandatory language courses after students have been admitted, based partially on proficiency scores, would likely present feasibility issues and thus, such an implementation may be viewed as discriminatory and neglectful of individual capabilities.

\section{Culture.}

Intercultural communication. Creating meaningful cultural exchanges on university campuses has been experienced as a challenging aspect of increasing student diversity (McGrath, 2010). Guo and Chase (2011) highlight the successes of the University of British Columbia's Centre for Intercultural Communications, created to provide a site for cross-cultural learning and sharing for all members of the university community. The outcomes of the Centre have pointed to the value of investing in a common multicultural space, allowing the university to fully maximize the diverse teaching and research experiences of its student body. Further, it is the site of cultural education for newcomer and international students on Canadian pedagogies, and academic and social language, and provides advising for staff and faculty on challenges and successful strategies for teaching and collaborating with 
international student populations (Guo \& Chase, 2011). UBC's approach highlights an important finding that echoes earlier work of Guo and Jamal (2007): the intercultural education model is as much about improving the mainstream understanding of diversity as it is about developing culturally aware and welladjusted international students. Furthermore, promotion of intercultural spaces, as opposed to international student-specific spaces, supports the notions of an evolving, diverse collective identity, essential to multiculturalism and harmonious cultural plurality (Dib, 2006).

Culture and academic life. Cultural barriers to academic integration can overshadow individual capacity to succeed. International students have expressed frustration with the lack of global content in course curricula, professors' misinterpretation of language problems, difficulty understanding the Western professor-student dynamic, and the relatively small number of institutions which provide support specifically for international students' academic acculturation (Myles \& Cheng, 2003; Guo \& Chase, 2011). Supporting this is the AUCC's (2007) finding, that while most universities offer non-academic student support services, less than half provide targeted programming to facilitate academic success for international students. Culture and academic success can also converge with different perspectives and different cultural expectations of education. Moores and Popadiuk (2011) recount an interview with a Chinese international student, who explained that Western education focuses less on students becoming "very useful people" (p. 297) and more on individual fulfillment of the person. This finding points to the importance of a two-way cultural adaptation, including the educational 
expectations of international students in support programming.

Peer mentoring. Partnering students for peer support is a valued component of many student life programs at Canadian universities. Pairing domestic students or more senior, experienced international students with newly arrived international students is an option for promoting inclusion and cultural exchange (Leask \& Carroll, 2011), and provides the opportunity for international students to use formal, institutionally organized programs to create informal peer networks (Dunn \& Oliver, 2011). Likewise, the AUCC (2011) has noted the success of peer mentor programs in assisting in the transition into university for Aboriginal students. The AUCC findings suggest the overarching benefits of peer-oriented support. Mendelsohn (2002) found that the pairing of NNES students and native English speakers in Lecture Buddy programs offset challenges of studying in English, contributed to academic skill development, and provided international students with opportunities to connect with their domestic counterparts, who were able to act as informants on Canadian academic life.

\section{International Student Support: Finances, Employment and the Labour Market}

Finance. Perhaps one of the greatest barriers faced by international students is the social construction of the group as 'designer immigrants' (Lowe, 2011; GatesGasse, 2012). This notion refers not just to the assumption that international students are ideal economic immigrants, in that they enter the labour market with skills, networks and language skills that ensure success (Lowe, 2011; Gates-Gasse, 
2012), but also to the perceived economic wealth of the population as a whole. Both scholarly literature (Cheng \& Fox, 2008; Zheng, 2010) and applied reports (CBIE, 2009) point to the different lived experiences of international students in Canada.

The Canadian Bureau for International Education (2009) has found that there are significant financial demands faced by international students in Canada, with almost half of international university students expressing financial stress. Scholarly sources find similar economic strains noting that the economic statuses of international students must be understood as diverse, with growing numbers of students from middle class families migrating for international education - a finding that contradicts the notion that all international students come from wealthy families (Waters, 2006; Zheng, 2010). Students surveyed explained the need to rapidly complete their program of study to reduce living costs or working long hours to make ends meet (Myles \& Cheng, 2008). Building on experiences of economic barriers, the CBIE (2009) study participants' most common recommendation for government and postsecondary institutions was to reduce international student tuition fees and provide the group with increased opportunities for scholarships and bursaries. Myles and Cheng (2008) and Simon (2014) argue that international students are not being afforded equal opportunity to gain a high-quality, well-supported education. The effects of a costly yet unsatisfactory post-secondary education gained at Canadian institutes directly and negatively impact the role international graduates are able to assume in the Canadian economy after graduation (Myles \& Cheng, 2008; Simon, 2014). The explicitly expressed financial stresses of international students 
demonstrate that finances are a barrier to the populations' success in Canada, supporting the CBIE (2009) survey results and the AUCC (2011) findings that decreased student funding may negatively impact enrolment. Further, the CBIE (2009) found that the relatively few scholarships and bursaries available for international students at Canadian institutions is a substantial push factor away from study in Canada. However, a push away from Canada merely means a loss of the global share of international higher education for the country. International students view the US as a more attractive study choice as it offers more scholarships despite higher tuition fees (CBIE, 2009). Generally, the literature focuses on factors other than economic support, perhaps indicating the commonly held belief that international students are in fact designer immigrants.

Employment. Two forms of employment are currently available to international students in Canada: on-campus and off-campus. Off-campus employment was cited in the literature as an important means through which international students could earn money and improve their English (Liu, 2011), create bridging social capital (Knutson, 2011), and feel a sense of belonging to the wider community (Knutson, 2011). Nevertheless, language and culture are critical factors in the job search process. The ability to connect language learning, academic study, and career planning is perhaps the most important advantage of international student employment, aside from increased income.

Research and teaching assistantships. Specific to international graduate students is the option of gaining on-campus employment as a research or teaching assistant. University funded employment is an important part of international 
graduate students funding packages if students are offered financial support along with an offer to study. International research and teaching assistants play critical roles in the dissemination of knowledge to undergraduate students, and make significant contributions to university efforts of internationalizing curriculum (Guo \& Chase, 2011). There are however, personal benefits to engaging with such work. Moores and Popaduik (2011) found that international graduate students who participated in international teaching assistant courses offered by the university were more easily able to navigate cultural and academic differences in their work and study.

Career Counseling. Career counseling is an integral function of modern universities. A longstanding characteristic of the counseling profession is the application of a multicultural approach, which, with the increased presence of international students, has become progressively more complex in practice (Arthur \& Achenbach, 2002). However, like many international student services, user rates are low (Gates-Gasse, 2012). Popadiuk \& Arthur (2004) suggest linking counseling with other international student services, while further work by the authors (Arthur \& Popadiuk, 2010) suggests career counselors integrate cultural orientation into their practice, as a means to connect with the individual circumstances of international students. This links to Moores and Popadiuk's (2011) work on culture and academic expectations, and the importance of understanding the educational goals of international students prior to creating programming initiatives to address perceived barriers. Likewise, Alboim (2011) points to the critical detail that not all international students plan to work in Canada after graduation, and these intentions 
must also be considered and included in programming and service agendas.

Social capital. Bridging and bonding social capital for traditional immigrant populations are commonly discussed as foundational building blocks of integration and inclusion (Aizlewood \& Pendakur, 2005; Putnam, 2006). It is argued that successful integration requires both forms of social capital. First, bonding social capital, which describes access to social resources within immigrants' ethno-cultural or linguistic communities. Second, successful immigrant integration requires opportunities to access and interact with the resources and members of other communities, referred to as bridging social capital. Thus, well-developed social capital has benefits of dual support, originating from within their communities and through access to other communities. Bridging social capital has benefits which include opportunities to gain better-suited employment, further language learning to high proficiency levels, and creating diverse social networks (Aizlewood \& Pendakur, 2005; Pendakur \& Mata, 2012). While the social capital theory has not been directly applied to the integration of international students and graduates in Canada, the application of the concept to the population has similar benefits to social capital building for traditional immigrant populations.

Labour market preparation. Despite the growing numbers of international students in Canada (Guruz, 2011) and federal policy intentions to integrate the population into the labour market (Lowe, 2011), few authors were able to discuss the merits of post-graduation employment readiness programs or strategies at universities, geared specifically toward international students. This is likely due to the lack of such initiatives, representing possible strategic resistance by university 
programmers in light of the ethical dilemma of retaining international student after graduation. Authors who included Memorial University of Newfoundland (MUN) in their analyses (Knutson, 2011; Gates-Gasse, 2012) discussed the value of the Professional Skills Development Program for International Students, offered collaboratively by the province and the university as a means to increase employer awareness of this potential labour pool and facilitate career employment for international students. This progressive programming agenda by MUN is a product of the province's 2008 Multiculturalism Policy, and the creation of grants and subsidies for newcomer support initiatives (Knutson, 2011).

Student perceptions of the Canadian labour market. The CBIE (2007) survey on international students and employment in Canada has found that the population perceives there are significant barriers to labour market entry. The barriers include discrimination in hiring practices and inconsistent policies that make staying in Canada difficult. Of the sample surveyed, two-thirds noted they would return to their home country or seek employment in another country, postgraduation. The other third who planned on remaining in Canada would likely encounter difficulties in transitioning from study to work, connecting with the misconceptions of employers surveyed who believed they were unable to hire international graduates (CBIE, 2007).

\section{Scholarly Recommendations for Support}

As different groups require different supports for success (Keynon et al, 2012), a more structured, adaptable university-wide system has been suggested to create an 
effective and inclusive learning community (Kamara \& Gambold, 2011). A threephase program has been recommended to streamline the international student experience through a set of centralized services and supports. The program consists of a period of transition and sociocultural adaptation; a period of promotion of tools for international students to self-resolve anticipated or real integration challenges; and, a partnership oriented phase, seeking to continually progress linguistic and cultural inclusivity in classrooms by encouraging staff, faculty and students to collaborate (Kamara \& Gambold, 2011).

Similarly, though more broadly, Snow Andrade (2006) finds that providing international student support is about building networks of services that can be individualized depending upon student need. International students face barriers and achieve success in areas that cannot be measured by quantitative measurements, such as GPA and retention, and thus universities must engage with international student populations to gain first hand knowledge of their needs and wants. Snow Andrade (2006) suggests that current support centres and faculty receive training on best practices for integrating international students into academic and social life on campus, to ensure collaborative success for universities and students (Snow-Andrade, 2006). Liu (2011) also makes suggestions for a new agenda of international student support, wherein all campus services and organizations can collaborate, each playing important roles in the acculturation of international students on Canadian campuses. 


\section{Section IV}

\section{Analysis}

\section{The Landscape: Past and Present}

Assessing the social inclusion of international students in Canada involves first, a discussion of the political landscape guiding the formation and implementation of policy influencing higher education and two-step immigration. "Embedded liberalism" (Banting, 2006, p. 417), characterized by a simultaneous liberalization of the economy and expansion of social security, has been ideologically overshadowed, and finally replaced by a paradigm insistent upon providing opportunities to gain knowledge and self-sufficiency rather than tangible support to ensure societal wellbeing (Banting, 2006). While this approach represents a well-orchestrated social investment strategy, it has de facto removed the state from responsibility to provide and protect, and has shifted this responsibility to the individual. This new policy agenda has transformed federal, and to some extent provincial, ideology and thus has influenced immigration policy, reconstructing the national migration strategy through a series of incremental changes, resulting in a massive system overhaul (Banting, 2006; Bauder, 2008). The outcome has resulted in a far-reaching neoliberal immigration framework, which like social policy strategies, seeks to economize well-being and prioritize self-sufficiency over equity. While immigration in Canada has long been a "structural necessity" (Bauder, 2008, p. 132), the 
economic utility of potential immigrants has been highlighted by a neo-liberal policy agenda. It represents a "race for talent" (Shachar, 2006, p. 105) as well as the introduction of temporary immigrants as a solution to the burdensome federal responsibility of past immigrant cohorts who struggled to succeed economically.

In 1973 Canada's Temporary Foreign Worker Program (TFWP) was created to address labour shortages in highly skilled professions, and remained a "lastresort" solution for employers fill job vacancies through foreign-born labour, until the 1990s (Nakache \& Kinoshita, 2010). Alongside the entrenchment of a neo-liberal policy agenda, the TFWP program expanded to include live-in caregivers, agricultural workers, and by 2002 included lower skill level jobs (Foster, 2012). In the spirit of liberalization, flexibility, and self-sufficiency, international students, a once strictly temporary population, were re-envisioned as a source of potential labour. Representing a pool of acculturated, economically capable, and linguistically advanced would-be migrants, the federal government began to reconfigure policies pertaining to international students shortly after the 2002 introduction of the Immigration and Refugee Protection Act (IRPA), Canada's reformed immigration framework. Significant modifications included the conditions under which international students could transfer between institutions, apply in country and online for study permits and renewals, and legally obtain employment in Canada both during and following postsecondary graduation. Such changes represented steps toward the 2008 creation of the Canadian Experience Class (CEC), a pathway to permanent residency tailored to fit the demographics and experiences of international students (CIC, 2010). 
Under the CEC, international students and economic migrants use their skilled work experience in Canada, Canadian acquired postsecondary education and advanced English language skills to apply for permanent residency (CIC, 2014). Representing a two-step immigration process, international students initially enter Canada as temporary immigrants, gaining the necessary skills and education for economic migration independently. Next, they obtain status as economic immigrants and via liberalized permanent residency programs including the CEC or PNP, and apply to stay in Canada permanently. These pathways to permanency highlight the federal reconceptualization of international students' presence in Canada and represent the culmination of past employment liberalizations for the population. Further, the pathways solidify the process of two-step migration as a permanent feature of the federal policy landscape (Gates-Gasse, 2010).

Due to the prominence of self-sufficiency under the neo-liberal agenda, international students, as temporary migrants, are ineligible to access most immigrant settlement services (Chira, 2009). Serving as quasi-sponsors, universities hold absolute responsibility to prepare international students for not only academic success, but also for success in Canada, long-term. This has created several key challenges and responsibilities for universities. In terms of challenges, universities are faced with financial burdens of the day-to-day operations of Canada's International Education Strategy. With already limited resources for student services, funds are required to be divided further to accommodate changing campus demographies and diversifying student needs (Kamara \& Gambold, 2011). Student services are funded through decreasing federal transfers by their respective 
provincial governments (Bakvis \& Skogstad, 2008; Guruz, 2011) and increasingly through student tuition and fees. Because of the user-fee model universities have been pushed to adopt, governments are criticized for exploiting the education system for wider economic gains, and with university administration citing the dynamic of international students as future economic migrants as ethically problematic (Gates-Gasse, 2012).

While this reframing of international students has only recently gained momentum in Canada, it is a product of globalization that has prioritized internationalized higher education and promoted domestic responses capitalizing on the international mobility of students (OECD, 2004; Guruz, 2011). The global agenda for higher education has resulted in a large-scale push of knowledge seeking students from newly industrialized countries without developed post-secondary sectors, toward post-industrialized societies with well-developed higher education systems (Guruz, 2011). Though the intention of initial migration may be circular, the Western race for talent has resulted in the retention of mobile students to benefit declining populations and strengthen the economies of the host state (Guruz, 2011). As with most effects of globalization, international student flows are a multidimensional phenomenon. International students have agency, intentions, and aspirations. Many international students in Canada report that international education is a means to achieving a better life in a new country (Arthur \& Flynn, 2011); conversely large portions of such students have intentions to migrate to a third country or back home after graduation, due to perceptions of better employment prospects elsewhere (CBIE, 2007). With multiple actors and strikingly 
different perceptions of success, international student policies must be analyzed and discussed in light of each stakeholder, and within a wide-reaching framework of social inclusion.

\section{International Students and Inclusion}

To create successful policy outcomes, the conditions for individual success must first be set. For many international students at Canadian universities, there are barriers preventing full contribution to Canadian society. The barriers that reproduce and reinforce social exclusion are dependent upon the structural design of policies and institutions, as well the characteristics of individuals granted entry into institutions, via polices and institutional governance practices. At universities in Canada, variation of international student needs, for example, ethnicity, language, race or religion, is not a primary programming consideration. The result is often homogenizing programs that further complicate integration rather than serving to support. This is perpetuated by the continued use of the umbrella term 'international students' when developing programming, thus overlooking the groupspecific international students needs, challenges and potential contributions. Keynon et al (2012) found that the normalized understanding of "international students" as non-native English speakers from newly industrialized countries, excluded Anglo international student populations from engaging with international student services, due to the lack of relevance to their group-specific settlement challenges. 


\section{Program Assessment}

An environmental scan was carried out to investigate the services offered by universities across Canada, and how they seek to include international students in programming agendas and recognize the group's unique challenges. The scan assessed four universities representing the four major regions of Canada: the University of British Columbia (UBC) in Vancouver, BC, representing Western Canada; the University of Calgary, in Alberta, representing the Prairies; Ryerson University in Toronto, representing central Canada; and Memorial University of Newfoundland (MUN) in St. John's, representing the Atlantic provinces. The universities were chosen to highlight regional variations in international student programming approaches nation-wide, and to reinforce the impacts of federalism on international higher education. Using the search function on university websites, searches were carried out by applying keywords representing core support domains identified in the scholarly literature: language, culture, academics, finance, employment and career. The keywords were paired with the specifying or filtering term "international student". The findings, detailed in Table 2, confirmed Alboim's (2011) observation that international student services have been downloaded onto educational institutions and in the process have become uneven in quality and consistency. Depending on the institution an international student chooses to attend, the quality of education and support varies substantially, thus resulting in vast differences in educational and labour market outcomes. 


\begin{tabular}{|c|c|c|c|c|c|}
\hline University & $\begin{array}{l}\text { Language } \\
\text { Support } \\
\text { Program }\end{array}$ & $\begin{array}{l}\text { Academic } \\
\text { Support } \\
\text { Program }\end{array}$ & $\begin{array}{l}\text { Cultural } \\
\text { Support } \\
\text { Program }\end{array}$ & $\begin{array}{l}\text { Financial } \\
\text { Support } \\
\text { Program }\end{array}$ & $\begin{array}{l}\text { Labour } \\
\text { Market } \\
\text { Support } \\
\text { Program }\end{array}$ \\
\hline \multirow[t]{2}{*}{$\begin{array}{l}\text { University of } \\
\text { British } \\
\text { Columbia }\end{array}$} & $\begin{array}{l}\text { Academic } \\
\text { English } \\
\text { Support } \\
\text { Program }\end{array}$ & $\begin{array}{l}\text { Academic } \\
\text { English } \\
\text { Support } \\
\text { Program }\end{array}$ & $\begin{array}{l}\text { International } \\
\text { House }\end{array}$ & $\begin{array}{l}\text { International } \\
\text { Tuition Award } \\
\text { / UBC } \\
\text { Graduate } \\
\text { Support } \\
\text { Initiative }\end{array}$ & $\begin{array}{l}\text { Regulated } \\
\text { Canadian } \\
\text { Immigration } \\
\text { Consultant }\end{array}$ \\
\hline & $\begin{array}{l}\text { Tandem } \\
\text { Language } \\
\text { Program }\end{array}$ & $\begin{array}{l}\text { International } \\
\text { Student } \\
\text { Academic } \\
\text { Advisor }\end{array}$ & $\begin{array}{l}\text { Access \& } \\
\text { Diversity }\end{array}$ & $\begin{array}{l}\text { Research/ } \\
\text { Teaching } \\
\text { Assistantships }\end{array}$ & $\begin{array}{l}\text { International } \\
\text { Student } \\
\text { Advisor }\end{array}$ \\
\hline \multirow[t]{3}{*}{$\begin{array}{l}\text { University of } \\
\text { Calgary }\end{array}$} & $\begin{array}{l}\text { English for } \\
\text { Academic } \\
\text { Purposes }\end{array}$ & \multirow[t]{3}{*}{$\begin{array}{l}\text { International } \\
\text { Student } \\
\text { Academic } \\
\text { Advising }\end{array}$} & $\begin{array}{l}\text { Global } \\
\text { Friendship } \\
\text { Program }\end{array}$ & \multirow[t]{3}{*}{$\begin{array}{l}\text { Merit-based } \\
\text { Scholarships/ } \\
\text { Awards }\end{array}$} & \multirow[t]{3}{*}{$\begin{array}{l}\text { International } \\
\text { Student } \\
\text { Advising }\end{array}$} \\
\hline & $\begin{array}{l}\text { English } \\
\text { Language } \\
\text { Program }\end{array}$ & & $\begin{array}{l}\text { Mentoring } \\
\text { Program }\end{array}$ & & \\
\hline & $\begin{array}{l}\text { Language } \\
\text { Bank }\end{array}$ & & $\begin{array}{l}\text { Orientation } \\
\text { Program for } \\
\text { International } \\
\text { Students/First } \\
\text { Year Graduate } \\
\text { Students }\end{array}$ & & \\
\hline \multirow[t]{2}{*}{$\begin{array}{l}\text { Ryerson } \\
\text { University }\end{array}$} & $\begin{array}{l}\text { English } \\
\text { Language } \\
\text { Support } \\
\end{array}$ & $\begin{array}{l}\text { English } \\
\text { Language } \\
\text { Support } \\
\end{array}$ & \multirow[t]{2}{*}{$\begin{array}{l}\text { Tri-Mentorship } \\
\text { Program }\end{array}$} & $\begin{array}{l}\text { Scholarships } \\
\text { /Awards }\end{array}$ & $\begin{array}{l}\text { International } \\
\text { Student } \\
\text { Advising } \\
\end{array}$ \\
\hline & $\begin{array}{l}\text { ESL/EAL } \\
\text { Certificate }\end{array}$ & $\begin{array}{l}\text { ESL/EAL } \\
\text { Certificate }\end{array}$ & & $\begin{array}{l}\text { Research/ } \\
\text { Graduate } \\
\text { Assistantships }\end{array}$ & $\begin{array}{l}\text { Career } \\
\text { Mentorship } \\
\text { Program }\end{array}$ \\
\hline \multirow[t]{3}{*}{$\begin{array}{l}\text { Memorial } \\
\text { University of } \\
\text { Newfoundland }\end{array}$} & \multirow[t]{3}{*}{ ESL Programs } & & $\begin{array}{l}\text { Culture-to- } \\
\text { Community } \\
\text { Program }\end{array}$ & $\begin{array}{l}\text { Graduate } \\
\text { Awards }\end{array}$ & $\begin{array}{l}\text { International } \\
\text { Student } \\
\text { Advising }\end{array}$ \\
\hline & & & $\begin{array}{l}\text { International } \\
\text { Student Advising }\end{array}$ & $\begin{array}{l}\text { Graduate } \\
\text { Assistantships }\end{array}$ & $\begin{array}{l}\text { International } \\
\text { Student Career } \\
\text { Advising }\end{array}$ \\
\hline & & & $\begin{array}{l}\text { International } \\
\text { Student Advising } \\
\text { Family Program }\end{array}$ & & $\begin{array}{l}\text { Professional } \\
\text { Skills } \\
\text { Development } \\
\text { Program }\end{array}$ \\
\hline
\end{tabular}

Table 2: Scan of International Student Services in Canada*

*See Appendix 
Language support. Common to all institutions were well-developed English language support programs. Ranging from traditional English support centres, to conversation partners and English for Academic Purposes courses, each university appears to have identified two important factors. First, that the composition of international student populations is changing: no longer are international students migrating from a small network of Anglophone countries, as in past years when the United States and United Kingdom were leading source countries (Statistics Canada, 2011). On campuses across Canada, growing populations of Indian, Chinese, Korean, and many other nationalities can be found, with each group representing a distinct ethno-cultural identity, along with very different English language abilities. Second, the acknowledgement of linguistic diversity and subsequent programming marks an important understanding in the expectations of international students. For many years an assumption was held in second language acquisition circles that because non-native English speaking international students were studying and often working in an English language dominant country, they would naturally acquire advanced English proficiencies (Ranta \& Meckleborg, 2013). Moving away from this perception of language acquisition is a significant step for universities, having created extensive networks of language support for their NNES populations, with increasingly limited financial resources.

Cultural support. While language components of the inclusion of international students were identified, the scan found less than satisfactory programming efforts to address student's acculturation processes. Excluding student-run cultural associations, other efforts to promote two-way cultural 
awareness were limited. Only UBC, with its Centre for Intercultural Communications, and MUNs Culture-to-Community program identified culture as a potential barrier to inclusion for international student populations. UBC's Centre for Intercultural Communications was developed in response to increasing diversity on the university's campus and the need for an inclusive site of two-way cultural exchange (Guo \& Chase, 2011).

Differing from International Student Offices, which all the universities in the scan had established, the Centre for Intercultural Communications aims to maximize the different life and learning experiences of faulty, staff, and students by engaging all stakeholders in meaningful cross-cultural exchanges. Intending to foster a collective university identity that promotes cultural plurality, the Centre focuses not only on supporting international students in their adjustment to Canadian culture, but includes training for staff and faulty on strategies for internationalizing curricula and collaborating with international students (Guo \& Chase, 2011). The Culture-to-Community program at MUN has similar, but less ambitious intentions, aiming promote cross-cultural understanding. Due to the program's target Canadian audience, K-12 students, meaningful results will take some time to have effect. Based on the information available on university websites, it is difficult to know whether course curricula are being adapted to engage international students, as all university websites claim to have internationally focused or multicultural campuses. The literature exposes a less promising side in respect to integrating culture into subject course work, with international students often explaining they feel responsible for adding the cultural dimension courses through class 
discussions, either as a student or a teaching assistant (Myles \& Cheng, 2003; Guo \& Chase, 2011). Such student perspectives clash with the International Education Strategy, which aims to internationalize curricula both at home and abroad (Govt. Canada, 2014a).

The relative lack of cultural inclusivity and intercultural awareness programming at universities located geographically between British Columbia and Newfoundland and Labrador is alarming. While Ryerson University and the University of Calgary each have agendas to promote cross-cultural interaction via peer mentoring programs, the onus is placed on the student body to prioritize intercultural sharing and engage with programs and international students. Just as government has downloaded immigrant settlement service responsibility onto provinces, municipalities and institutions (Evans \& Shields, 2000), universities have downloaded cultural integration, and to some extent social inclusion practices, onto its students.

Academic support. Language and culture intersect in the academic lives of international students. English for Academic Purposes (EAP), thus, could be used as a tool for inclusion for NNES international students, who are increasingly representative of international student bodies. Acknowledging the differing pedagogies, language skills, and social behaviours required for success in higher education in Canada, EAP could provide international students with applied language skills that integrate and advance them into academic life. Simultaneously, programming must acknowledge the different and valuable knowledge that international students bring with them to Canada. With well-established English 
language support systems in place at all four universities in the international student-programming scan, each included some form of EAP agenda (see Table 2; see Appendix). However, the quality of these attempts to fuse language, culture and academics may not be enough to engage international students to participate.

According to the Canadian Bureau for International Education's 2009 survey, only 12 percent of international students at Canadian universities utilize learning support services. The underuse of EAP and academic supports available to international students points to the necessity of programs to work in tandem with outreach, and to include students in the development of EAP programs. Due to the promotional nature of university websites the actual effectiveness of EAP and general language support programs at the universities scanned is unknown. However, based on the literature it appears that students are not engaged by the content or delivery style of such services. Liu (2011) explains that the importance of the role of targeted language support should focus not solely on ameliorating proficiency struggles, but also on cultural adaptation and the creation of social capital.

As per the findings of several studies (Berman \& Cheng, 2001; Cheng et al, 2004; Cheng \& Fox, 2008), there is a distinct need for well-designed EAP, as NNES international students continue to cite presentation skills, class participation, and critical writing as the most significant barriers in their academic acculturation. For many international students these academic skills were not included in their prior learning environments. From the social inclusion perspective, EAP works to dismantle the barriers of culturally infused academic language, and seeks to 
overcome the challenge though collaborative program design. However, if carried out via an inclusionary programming agenda, EAP initiatives must be voluntary despite a suggestion in the literature that all NNES international students be automatically enrolled (Cheng et al, 2004).

Labour market readiness. Federal policy aligning international students with the labour market makes salient the aforementioned strategies for language, culture and academic support. Without language skills and cultural competency of Canadian life, international students are at a great disadvantage in an already competitive job market. However, as experienced by Canada's economic immigrants, there is much to be learned about labour market entry, beyond qualifications. For international students, the process of job preparedness begins during the study period, and thus requires special programming by universities. However, only MUN with its job readiness program, and Ryerson's career mentorship included employment oriented programming (see Table 2). At the federal level, post-graduation employment barriers have been partially acknowledged through policies facilitating early contact with the Canadian labour market, specifically the Off-Campus Work Permit Program (OCWPP), and more recently through the inclusion of part-time work privileges in study permits (Govt. Canada, 2014b). It is important, in this context, to question if liberalizing employment rights, through federal programs such as the OCWPP and the PGWPP, promotes equitable participation in the labour market for international students. That is, does entry to the labour market mean equality in employment outcomes? The social inclusion perspective suggests that it is not only federal programs that 
cause international students to struggle in their labour market entry, but rather the conditions the programs create through undefined objectives. Thus, dismantling the barriers of access to employment through labour liberalizing policies should be complimented with programs that work in unison with subject study to inform international students on the Canadian job market and provide opportunities to build bridging social capital.

Career development. Alongside labour market readiness programs universities should create intuitive career programming agendas. Given budgetary constraints, a result of governmental austerity, and paired with a political climate of neo-liberalism, this type of programming should be promoted rather than impeded. Both social inclusion and policy success require international students to have access to the tools necessary to thrive in society. For international students, matters of language and culture can manifest as barriers to societal success. International student-specific career development support was limited to International Student Advising present at all universities (see Table 2). Descriptions of the type of support offered by these advisors often noted career services (see Appendix), however, it may be assumed that international students would be referred to co-operative education programs or general career services.

Because there are no visible support systems that allow international students to receive training to overcome barriers, their education in Canada does not translate into the success that policy has envisioned. In an increasingly globalized world, international students possess vital skills that paired with higher education, position them as extremely desirable employees. However, there is a 
mismatch between the ability of international students to positively contribute economically and the prevalence of labour market successes experienced. Facing barriers such as absence of knowledge about the job market, underdeveloped local networks, and general lack of job readiness, international students are entering the labour market at job levels much lower than their qualifications. This echoes experiences of economic immigrants to Canada, who despite advanced qualifications and significant job experience, are underemployed (Bucklaschuk \& Wilkinson, 2011).

Finances. At the heart of employment, is finance. For international students, financial concerns are a complex issue. While it is true that international students are self-funded, many report experiencing financial hardships that compromise the benefits of an international education. According to the Canadian Bureau for International Education's 2009 survey of postsecondary international students, 40 percent of international students attending universities expressed that their financial situation was a significant problem. The university scan found limited funding opportunities for international students, with the majority of such financial supports targeted at international graduate or doctorate students (see Table 2). The need for financial incentives to study in Canada will continue to grow along with the demand for international education and the propensity of international students migrating from middle class families from newly industrialized countries (Waters, 2006; Zheng, 2010). Despite federal commitment to funding scholarships for international students (Govt. Canada, 2014a), steadily increasing numbers of international students at Canadian universities and relatively few funding 
opportunities make such efforts insignificant.

Employer engagement. Results from CBIE's (2007) survey on international graduates from Canadian institutions paired with the populations' experiences with Canadian labour market entry, illustrate conditions for what Castles (2004) describes as policy failure. Castles (2004) explains: "policy failure can be said to occur when a policy does not achieve its stated objectives" (p. 854). Considering the objectives of Canada's International Student Program, PGWPP, CEC, and the International Education Strategy, CBIE's (2007) findings that international graduates are deterred from seeking employment in Canada due to unclear policies and fear of discrimination in the workforce, are troubling. Two-thirds of international graduates in Canada will either return home or seek employment in other countries (CBIE, 2007). More problematic is the misunderstanding by employers that they are prohibited from hiring international students or graduates, an unsettling reality for the one-third of such students who choose to remain in Canada after graduation (CBIE, 2007). Because the federal government has done little in the way of promoting its liberalized migration schemes for international students post graduation, for example the PGWPP, the private sector has limited knowledge about the pool of skilled, locally educated labour. This indicates that the International Student Framework may in fact be a "policy failure" (Castles, 2004, p. 854).

The international student service-programming scan found only one incentive to promote employer awareness of international graduates entering the Canadian labour market. MUN offers international students approaching graduation 
from either undergraduate or graduate programs a semester-long Professional Skills Development Program that builds employability skills, informs students of Canadian work culture, and connects students with the local business community to build networks (see Table 2) (Gates-Gasse, 2012). This program compliments career advising/counseling, building a dual practical-emotional network of support. The literature on international student career development points to this type of service as beneficial in the population's labour market readiness, and thus an integral piece in the social inclusion agenda.

Social capital. Three-quarters of the universities in the programming scan offered international students career advising or counseling (see Table 2). UBC did not advertise the availability of such services, having no explicitly labeled labour market preparation programs. Ryerson University pairs career counseling with a career mentorship program, building on the institution's well-developed counseling and mentorship framework. Ryerson's Career Mentorship Program and MUN's Professional Skills Development Program each direct focus towards the creation of social capital for international students, building bridges and creating bonds between individuals. However, based on the above areas of employer engagement and labour market readiness, more can be done to connect international students with resources to explore labour market options. Traditionally applied to permanent immigrant groups living in communities with only co-ethnics, bonding social capital is understood as the relationships with co-ethnics that comforts, reduces culture shock and provides close social networks for personal and family support (Putnam, 2006; Pendakur \& Mata, 2012). Conversely, bridging social capital 
represents the more difficult to form relationships with members not affiliated with an immigrant's ethnic community. However, once established these connections hold extensive benefits to an immigrant's wider social integration, often resulting in jobs matching an immigrants qualifications, rather than survival jobs available within the ethnic community (Putnam, 2006; Pendakur \& Mata, 2012).

Similarly, the social capital theory is of great importance to international student populations' labour market and social inclusion. While the group arrives in Canada temporarily, in order to fulfill policy goals of transitioning to economic immigrants and later to permanent residents, both forms of capital are requisites. By assuming that international students are capable of making ties to the native Canadian community without tangible support to do so, assumes that their age and Canadian education negates the struggles of the immigrant experience in Canada. This is not only untrue, it also represents a refusal by Canadian governments to acknowledge the different forms of knowledge and types of experiences international students bring with them, which in itself is a form of discrimination and exclusion.

In relation to the job market and social inclusion in general, social capital theory can be applied to international student populations in the same way that it is applied to traditional immigrant populations. As noted in previous sections on language acquisition, international students find it significantly easier to form ties with co-ethnics. The literature has found that while these bonding social ties provide a form of emotional well-being, such relationships hinder students' capacity to reach high English proficiencies. Independently, international students make 
connections with fellow international students through the shared experience of language struggles and an identity of otherness (Myles \& Cheng, 2003). In similar fashion to the struggles of language learning, the underdevelopment of international students' bridging social capital for labour market integration, i.e. relationships with Canadian students and employers, reduces their capacity to transition from student life to employment that corresponds with qualifications. Thus, social capital theories must be merged with the principles of social inclusion in order to achieve international student policy success.

In practice, this can be approached by unification of the intended outcomes of international student programming. For example, if the purpose of all international student services is to assist non-domestic students in achieving success during (and potentially after) their studies, then it can be said that social inclusion is the end goal. Thus, social inclusion, as the dismantling of barriers and the promotion of practical solutions for full and equitable participation in social life, requires the incorporation of social capital. By laying the groundwork for international students to build relationships, partnerships, and meaningful experiences using the tools provided through student services, the populations' presence in Canada could be mutually beneficial for students, communities, universities and governments.

Peer mentoring. Based on findings from the literature, peer mentoring programs partnering international and domestic students have yield positive results. However, these benefits have been limited to facilitating referrals to student services and campus events, increased participation, and generally heightening the 
sense of belonging felt by international students (Leask \& Carroll, 2011). The university programming scan found that only Ryerson's Tri-Mentoring program and the University of Calgary's Global Friendship program present peer mentoring explicitly as an integration and inclusion tool. It may be that peer mentoring is offered as a departmental feature and due to the wide-reaching target population of such programs, are not connected to international students specifically on universities websites.

While beneficial in terms of emotional well-being, the outcomes of peer mentoring programs appear to be superficial in relation to international students' long-term social inclusion. Should university peer mentoring programs seek to create bridging social capital in their programming agendas, and compliment student mentoring with professional mentoring, it is likely that other careeroriented services, presently underused by international students, would increase as well. By blending access to informal networks through institutional avenues (Dunn \& Oliver, 2011), the design of federal programs to utilize international students' Canadian education as an integration facilitating tool would be considerably more effective.

Assessed as a unit, it appears that the approach taken by universities to support and integrate international students into the university community, Canadian society, and the Canadian labour market is insufficient. No guiding mission statement to address the unique service needs of international students was found in the programming scan. Likewise, no organizational framework was found to be in place to address the gaps in international student services. Coordination was noted 
in the literature as imperative for successful program outcomes (Snow Andrade, 2006; Albiom, 2011; Kamara \& Gambold, 2011; Lowe, 2011), and so the fragmented approach to service provision at present provides grounds for pessimism. As noted above, the least developed programming area as it relates to the core barriers for international students, was labour market support. This may mark a decisive action by universities to reduce their participation in fulfilling governmental policy objectives. As MUNs collaborative labour market programming highlights, the presence or absence of employment readiness programming may signify the type of relationship postsecondary institutions have with the their respective provinces. That is, whether collaborative initiatives are positive and welcomed by universities, or if postsecondary institutions are unsatisfied with provincial and federal postsecondary interventions and would prefer to maintain a level of autonomy. This is an important area of research that is beyond the scope of this project, however, the implications of these relationships will play key roles in the steps both government and universities are willing to take in the social inclusion of international students. 


\section{Section VI}

\section{Recommendations}

\section{The Pathway Approach to Service Provision}

The above analysis of university programs servicing international students, points to the need for a new service model for post-secondary institutions. Based on the findings from the university-focused literature (see Section III) and programming scan (see Section IV) the recommendations below are exemplified using the university as a setting. However, with slight modifications the pathway approach suggested can be applied in all designated PSE institutions in Canada. The pathway approach uses Kamara and Gambold's (2011) pilot study as a basis, but adds to it dimensions of social inclusion and federal policy success. The 2011 study offers the first day of international students' study period as the starting point for restructured international student support framework, consisting of three phases. The first phase provides tools for transition into the academic environment and the campus as whole, in a "sociocultural grace period" (Kamara \& Gambold, 2011, p. 27) that includes information on expectations and strategies for self-assessment. The second phase uses the information from self-assessments and positions the university and its departments as the primary service provider (Kamara \& Gambold, 2011). This second phase includes many of Liu's (2011) recommendations that highlight the importance of international students' taking control of their success through "autonomous learning" (Liu, 2011, p. 78). However it situates universities as key actors, creating opportunities for international students to become confident 
and contributing members of the community. The third phase echoes Guo and Chase's (2011) evaluation of intercultural communication departments, and provides university staff and faculty with sociocultural training to support increasingly diverse international student populations. Positioning members of the teaching and administrative community with experience educating or working with international students as facilitators, learning and information sharing sessions are provided to promote the use of cultural competency models campus wide. All staff and faculty in Kamara and Gambold's (2011) three-phase model are required to familiarize themselves with common struggles of international students, the services available to assist in overcoming these struggles, and fair and balanced methods for addressing these barriers to success. Such training acknowledges that the classroom is the primary, if not only, site of exchange and interaction for many international students.

While valuable in its own right, the three-phase model offered by Kamara and Gambold (2011) lacks the capacity to successfully fulfill federal policy, while simultaneously creating the conditions for social inclusion. The proposed pathway approach segments the international student experience into several, nonsequential pieces and allows administrators to monitor students' progression and designate responsibility to the best-equipped departments (see Figure 1 below). A pathway approach recognizes that time spent at a university or in a country does not necessarily dictate the type of problem encountered and in turn cannot intuitively decide the type of support required; similarly students' cultural, religious, ethnic or linguistic backgrounds cannot be used as a basis for service 
referrals. International students may choose to revisit parts of a pathway during their international education experience.

The combination-style service model put forth below is substantiated by Moores and Popadiuk's (2011) finding that international students have differing expectations of their international education experience, as well as Alboim's (2011) comment that not all international students plan to stay in Canada after graduation. Providing extensive labour market services to international students who are strictly educational sojourners is not intuitive programming. Likewise, providing cultural support to international students who have completed secondary studies in Canada may not be required. Rather, a service approach that educates international students early is the basis of the pathway approach, providing agency through inclusion to make informed decisions on their investment in international education. 


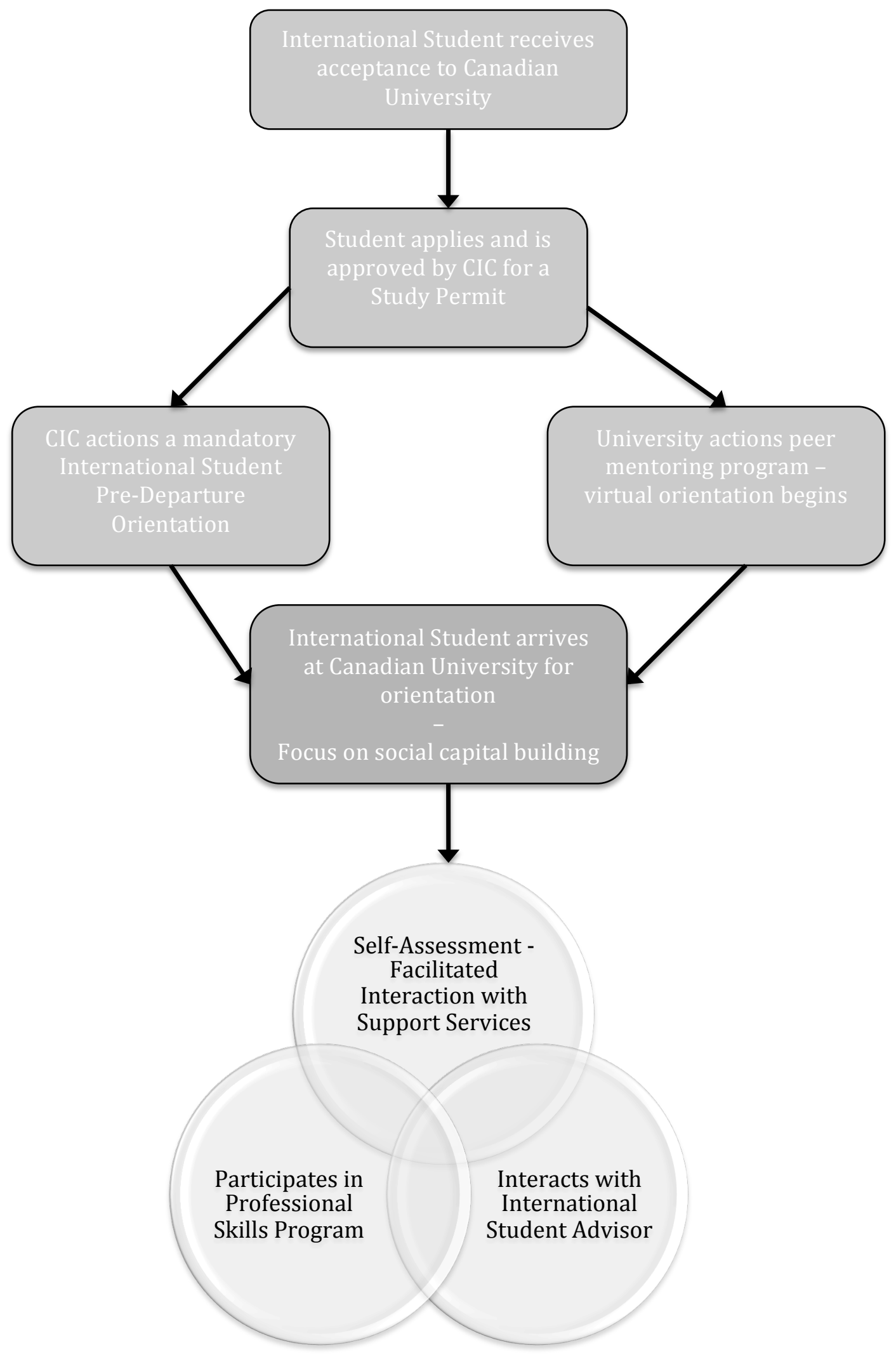


Before students arrive on campus universities establish their pathway model by initiating communication with students on preparation for success as an international student. In light of the volume of information received regarding immigration and course selection, it is recommended that universities action a peer mentoring program that begins virtually. Using this approach, international students are paired with a current student upon acceptance to university, with whom they have online communications prior to departure, and meet on arrival. This provides a connection to the university and the Canadian community immediately, and begins the process of acculturation prior to commencement of studies or arriving in Canada (Snow-Andrade, 2006). At present this structure is only in place under Mitacs Globalink program for visiting researchers (Mitacs, 2012), but has valuable potential in the successful integration and social inclusion of international students in Canada, regardless of their level of study.

The first weeks at university set the stage for international students level of engagement for the entirety of their international education experience. Orientation provides an opportunity for international students to make informal connections through institutionalized avenues, creating a sense of belonging to campuses, and begin the process of building bridging social capital. Paired with the campus information gained during their online communications with peer mentors, orientation can instill in international students the benefits of creating local connections rather than merely introducing students to services.

During orientation, the pathway approach includes both integrated social and academic opportunities with domestic students, as well as targeted sessions for 
international students. This uses Kamara and Gambold's (2011) socio-cultural grace period as its foundation, but adds to the self-assessment component facilitated interactions with campus services. For example, if during self-assessment a student addresses their challenges with time management, they are referred to the student success strategies unit at the university for a consultation. By providing international students structured opportunities to interact with the services they are recommended, the insecurity of making the first contact will be alleviated, and will boost typically underused student services, as per the evaluative literature on the subject (Popaduik \& Arthur, 2004; Gates-Gasse, 2012). This process in the pathway approach requires very little from universities in terms of resources. Instead it encourages students to self-advocate and actively participate in their social inclusion.

With roots in social inclusion, the pathway approach focuses on the mechanisms of institutions, such as the university, to equip once excluded populations with the tools for active and equal participation. As this analysis has highlighted that the university is positioned as an institution with the capacity to instigate such change for international students, through coordination with other key stakeholders. Following the orientation and self-assessment periods of the pathway approach, university administration appoints international students an advisor. Based on the current roles of international student offices at universities, and the demand they face in serving large and homogenized populations (CBIE, 2007), it is recommended universities appoint an advisor to each student, at a ratio of $1: 30$, to increase the frequency and duration of contact in this capacity. Research 
shows that international student populations typically do not visit career counselors at universities (Popaduik \& Arthur, 2004; Snow-Andrade, 2006; Gates-Gasse, 2012). This underuse is not caused by international students' perception that they do not require assistance; findings from the CBIE (2007) survey note that international students recognize that their integration into Canadian society will be difficult. Rather, the rationale for this underuse of counseling and advising is based on the assumption that such services are for crises and not support (Popadiuk \& Arthur, 2004).

To overcome the culturally based suppositions about career counseling, and to promote interaction with career support services, Popadiuk and Arthur (2004) suggest applying the cultural formulation approach used in psychology. This approach encourages counselors, and student service providers, to unpack terminology for their diverse cliental (terms such as 'career' and 'counseling'), apply students' cultural orientation to their advice (collectivist vs. individualist), and address immediate needs as well as long-term goals (Popadiuk \& Arthur, 2004). The international student advisor works in conjunction with peer mentors, meeting with students periodically to discuss progress, outcomes of services used, and methods to improve student and social life. Consistent interaction with both a peer mentor and an advisor ensures that international student needs are being met on an individual basis; a function a phase approach cannot accommodate due to its linear progression and assumption of layered skill development. One of the key benefits to a pathway approach is that students requiring a new type of support, regardless of their time since arrival, have personal connections with campus contacts to facilitate 
success.

Acknowledging the barriers to success and offering interactive support mechanisms to facilitate the shift from exclusion to inclusion is an important differentiation between the social exclusion framework and the social inclusion framework. This reiterates McGrath's (2010) view that student activism and institutional advocacy have strikingly different capacities to instigate change. The former working to draw attention to the victimization caused by exclusion, and the latter doing the same yet moving beyond recognizing exclusion, and seeking to partner with exclusion's victims to overcome barriers and institutions to dismantle them. In practice this segment of the pathway approach can mitigate a number of unmet needs. For example, many NNES international students begin subject-study in English for the first time in Canada and are not aware that they require support, as they have been successful in their English language studies prior to Canadian university. This may take some time to identify as students progress through their first or even second semester; having regular check-ins assures that barriers begin to be dismantled upon identification. The advisor and peer mentor work jointly in referrals, providing ongoing support to students and recommending programs that may suit the students' current academic, social or employment needs.

International students receive a significant amount of information prior to arrival on campuses and during orientation, often in a second language. It is unreasonable to expect that tools and resources offered during their first week on campus will be easily remembered and applied later. For instance, an international student approaching the end of their second year of a four-year program may decide 
they would like to stay in Canada after graduation. They may remember the importance of CIC's language criteria in the process, but not recount the critical value in making labour market connections or gaining Canadian experience prior to the job search process. Including support along the international student trajectory from arrival in Canada to graduation promotes federal policy success. The type of success that the social inclusion perspective aims for, using the pathway model, especially in light of heightened involvement of the multi-sectoral stakeholders, is not the mere filling of jobs in the Canadian labour market by international graduates. Rather, it is interaction with the labour market plus the active participation of international graduates in building meaningful careers and lives in Canada.

Though the significant economic losses of underutilization of immigrant skills are well documented- estimated at a loss of between $\$ 4.6$ and $\$ 5.9$ billion annually (Hire Immigrants Ottawa, 2013), little is being done currently to expand measures to correct losses through outreach by businesses to international students/graduates. In order for universities to build systematic, practical, and sustainable partnerships with the private sector, the provincial government must become involved. Newfoundland and Labrador made great strides in addressing provincial labour market needs by connecting the private sector with graduating international students, and engaging Memorial University of Newfoundland (MUN) to implement a Professional Skills Development Program on labour market readiness. Other provinces would likely experience similar successes to those of Newfoundland and Labrador should post-secondary-provincial partnerships be 
formed.

In a pathway approach, international students have access to the private sector over the course of their program of study. Thus, those students who have adequate language and academic skills, achieved through on-going support and targeted programming, and who have expressed interest in gaining Canadian experience, are enrolled in a university-employer collaborative program, like the Professional Skills Development Program offered by MUN. This process is facilitated by the advisor and offers students the option to begin labour market preparation well before they seek employment as graduates. Transparency is a key component of the pathway model and so, job search and labour market demands must be revealed to students before they commit to remaining in Canada, requiring coloration with government bodies. Similarly, transition-out programming will become a necessary feature for international students who must apply the multiple functions of their university skills to other domains of social life.

By fostering partnerships, a pathway approach attempts to connect each member of the university community with knowledge on creating and maintaining the conditions for inclusion not only for international students, but the community as a whole. Kamara and Gambold (2011) suggest an insightful measure that works well within a pathway model. They recommend the engagement of experienced international students as knowledge ambassadors to act as informants on the challenges faced by international students, bridging this knowledge with various departments across the university. Additionally, they could advise on the opportunities often missed by staff and faculty to engage and support the 
population. Extending beyond the classroom and into the various university student service units, cultural competency models used in classrooms and lecture halls should be shared with writing centres, mentoring and counseling units, student unions, and athletics departments to ensure that the pathway model serves its users well. The pathway approach is a cost-saving method, integrating international students into mainstream student support, therefore amplifying the importance of educating student service providers on challenges unique to international students.

A pathway approach is about sharing information and creating an inclusive community for all members, about putting into action the ideas of multiculturalism and equity. That is, it is about socially powerful institutions recognizing the challenges of marginalized groups and affording members the opportunities to engage with these institutions and enjoy full participation. While the pathway approach applied here focuses on the service and integration needs of international students, it can also be applied for Aboriginal students, populations with mental health issues, or first generation postsecondary students.

\section{New Approaches for Social Inclusion}

Simon (2014) notes, "enlightened international education policy is shifting from a focus on revenues generated by inbound international students, to a broader and more sophisticated approach" (p. 17), an especially salient point given federal policy intentions regarding the population. To achieve true policy success, services and opportunities must be accessible to international students through the fulfillment of the commitments of the International Education Strategy, including "the 
commitment to diplomacy of knowledge [...] giving the next generation of Canadian and international students the tools they need to contribute to global society in meaningful ways" (Govt. Canada, 2014a, p. 18). By ensuring equity in the practice of international education federal policies such as the PWGPP and the CEC can be realized. To that end, the following recommendations are advanced to open a dialogue on the multidimensional, multi-sectoral issue of international students' ability to participate fully in social life in Canada. The framework of recommendations is rooted in the principles of social inclusion, and agrees with the perspective taken in two recently commissioned reports by the Canadian Council of Chief Executives (Cappon, 2014; Simon, 2014). Each author calls for the immediate establishment of a national administrative approach to post-secondary education with significant involvement from the private sector. As such, the remainder of this section will be broken down by sector (see Table 3, below), and will then recommend the use of an alternative student services model for use at the postsecondary level.

\section{The Federal Government}

The social inclusion of international students begins at the federal level, because of the federal facilitation of international students in Canada via policies, and promotional initiatives of international education through the Imagine Education $\mathrm{au}$ /in Canada campaign. Federal support requires acknowledgement that the policies and programs increasing the number of international students in Canada, as well as the policies facilitating international students transition to economic class 
immigrants, must be paired with resources to sustain such migration. As an ideal first step this would take the form of increased transfers from the federal to provincial governments. Increased transfers would augment tuition fees paid by international students and would carry conditions that funds be allocated to establish a well-developed, centrally coordinated network of on-campus services that aim to promote social inclusion and the creation of bridging social capital.

In respect to the conditionality of additional funding to the provinces for the creation and/or expansion of international student supports at post-secondary institutions, CIC should consider expanding the 2014 designation system for educational institutions wishing to accept international students (see Section II), to include a programmatic designation. This could entail creating minimum standards for the types of programs institutions must offer, which would be federally supported by the increased funding via provincial transfers for international education initiatives.

Working together with the above pathway approach, CIC should begin information sharing with international students applying for study permits. This could work to increase awareness of employment options during studies and after graduation, and responsibilities to meet specific criteria, should students choose to stay in Canada post-graduation. Such a pre-departure orientation mirrors the Canadian Orientation Abroad programming offered to immigrants by CIC (CIC, 2012), and similarly uses web-based and in person sessions to educate international students on their journey ahead. By providing international students with immigration and settlement information early, federal policy intentions relating to 
international students are much more likely to be fulfilled.

Additionally, the CIC settlement-funding model should be expanded to include international students as eligible to use immigrant settlement services. While recent changes further limiting access to temporary foreign workers, refugee claimants and naturalized citizens point to disconcerting trends in the boundaries of services (Vineberg, 2014) the long-term economic intentions for international students should position them within the qualifying boundaries for CIC-funded settlement services. The immigration experience in Canada is understood as a continuum that requires ongoing support, positioning the current funding model between CIC and settlement service providers as ineffective (Chira, 2009). 


\begin{tabular}{|c|c|}
\hline The Federal Government & $\begin{array}{l}\text { - Participate in creation of intragovernmental } \\
\text { framework for international education } \\
\text { Increase transfers to provincial governments } \\
\text { with conditions to fund PSE programming } \\
\text { targeted at international students (NB: New } \\
\text { funding should not include matching } \\
\text { requirements) } \\
\text { CIC: expand settlement funding model to include } \\
\text { international students; restructure model to core } \\
\text { funding rather than project-based } \\
\text { CIC: redesign web-based communications to } \\
\text { increase employer awareness of hiring } \\
\text { international graduates } \\
\text { Extend institutional designation process (see } \\
\text { table 1) to standardize and include minimums of } \\
\text { international student specific programming } \\
\text { Create outreach and workshop agendas for } \\
\text { engagement of private sector }\end{array}$ \\
\hline The Provincial Governments & $\begin{array}{l}\text { - } \begin{array}{l}\text { Participate in creation of intragovernmental } \\
\text { framework for international education }\end{array} \\
\text { - Allow increased federal presence in post- } \\
\text { secondary administrative activities, specifically } \\
\text { those relating to international education } \\
\text { - Engage Private Sector in collaborative } \\
\text { international education projects } \\
\text { - Create outreach and workshop agendas for } \\
\text { engagement of private sector }\end{array}$ \\
\hline The Private Sector & 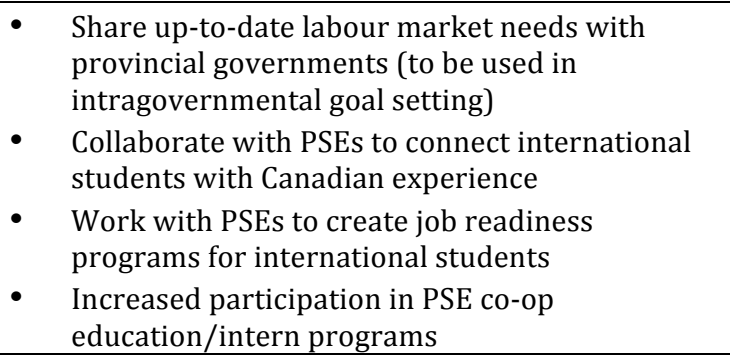 \\
\hline Post-Secondary Institutions & 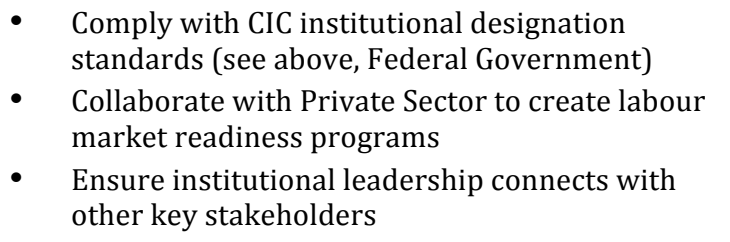 \\
\hline
\end{tabular}

Table 3: Policy Recommendations for Stakeholders of International Education. 
The inclusion of temporary migrants such as international students as eligible for consumption of federally funded settlement services should take place along with the reconceptualization of the project-based funding scheme, moving toward a core funding model. As settlement service providers annually await their funding approvals they are forced to issue layoff notices to their staff and seek highinterest lines of credit to cover expenses. While the majority of funds distributed to settlement service providers are granted to deliver government programs, there are little or no resources allocated to cover costs beyond program-related expenses. Overall the conditions attached to federal immigrant settlement service funding effectivity compromises the entire system, and thus requires massive overhaul (Vineberg, 2014). The first change on the part of the federal government requires acknowledging that settlement services are a permanent feature of the Canadian social service agenda and thus reorganizing the way in which funding is distributed (Vineberg, 2014). Additionally, as immigrants to Canada are increasingly temporary, and policy and economic success rely in part on the contributions of non-permanent immigrants, it is both ethical and logical to extend settlement services to such populations.

The immigration information employers have access to via CIC websites has created a climate of confusion, specifically in respect to hiring international graduates, and thus is a barrier for international students to build bridging social capital both during and following studies at Canadian institutions, and create conditions for policy failure. CIC websites should be redesigned to provide clear immigration parameters for employers interested in hiring international students. 
The problematic structure of CIC's web-based information system noted by CBIE (2007; 2009; 2013), predate Simon's (2014) recommendation that the federal government, CIC, and Imagine Education au/in Canada redesign websites to effectively communicate information. This is a much-needed step to catch up with Canada's international education competitors, namely Australia. The featureless web-based information outlets are in opposition to the International Education Strategy's objective to develop enhanced marketing and branding that resonate with the Strategy's priority markets, and to promote the private sector to increase engagement with education initiatives (Govt. Canada, 2014a). With countries such as Vietnam and India as primary target regions, a streamlined information system for both students and prospective employers is crucial due to the geographic positioning of the targeted markets, and their proximity to and attention from other, perhaps more efficient, providers of international education.

\section{The Provincial and Territorial Governments}

At the provincial level an inclusion-based approach requires the acknowledgement that post-secondary education, while technically the sole jurisdiction of the provinces, is in fact a shared responsibility under Canadian federalism. This shared responsibility is reflected in the mandatory transfers from the federal government to the provinces, to ensure that consumers of education Canada-wide are receiving a product of a similar standard. Further, the long-standing research and development councils represent the entrenched federal presence in the operation and advancement of post-secondary education. However, the sharing of educational 
administration is increasingly important due to the federal government's focus on international education and the creation of immigration policies that facilitate twostep migration, with users often transitioning through PNPs. This is multiplied further by the federal facilitation of international students in Canada without supplementation of PSE funding.

As Canada's education system continues to internationalize and once local programmatic issues are blended with issues of national security, trade, and population management, it is a logical progression to have adequate representation by both levels of government in higher education affairs, beyond the current federal presence in research and development. As Australia's education minister stated on international education in 2013, "its not just about education [...] It is about Australia's soft diplomatic capacity" (Simon, 2014, p. 8). As a nation outperforming Canada in international education, it may be useful to integrate positive functions of the Australian approach into the Canadian method of international education.

By forming a new type of federal-provincial relationship around international post-secondary education focusing not only on research and development but also on administration, it can be expected that funding for core programs would increase and in turn student programming agendas would have the capacity to respond the needs of international student populations. The health care system and the Canada Health Transfer exemplifies the benefits of this type of federal-provincial relationship (Canadian Federation of Students, 2013), ensuring that resource allocation by the federal government to the provinces remains consistent, and that provincial governments are able to fund permanent projects. As 
per the recommendations by Cappon (2014), there is a necessity for an intragovernmental framework to oversee the both the federal and provincial interventions in education, one that sets goals and manages growth through collaborative and strategic design. The past provincial disappointments of federal involvement in PSE could be avoided in international education specific collaborations by ensuring the funding directed toward universities is able to be utilized without matching requirements from other sources (Bakvis, 2008). Funding matching was a key area of strain following the establishment of the Canadian Foundation for Innovation, which supplemented PSE operational costs, a barrier due to the requirement that institutions cover 60 percent of costs from other sources. In provinces with a weak industrial base, such as those in Atlantic Canada, this often meant funding from provincial governments not originally intended for PSE use (Bakvis, 2008).

Issues of autonomy are amongst the most contested in recommendations for increased collaboration between the federal and provincial governments. A key area of concern is quality of education, which connects to the social inclusion perspective regarding international students in Canada. The lack of common standards in post-secondary quality assurance is hindering the prosperity of international students (Meekison, 2011), due to the programmatic and tuition discrepancies between provinces, and in turn has resulted in a fragmented system through which international education is provided. With each province having an autonomous ministry of education regulating PSE within its jurisdiction, the presence of national educational leadership bodies such as the Association of 
Universities and Colleges of Canada (AUCC), the Council of Ministers of Education, Canada (CMEC), and the Canadian Bureau for International Education (CBIE) have ambiguous roles in the coordination of PSE activities on internationally. While the ethical concern of autonomy in education raised by post-secondary administrators is valid in some respects, for example in approving degrees that match regional needs (Meekison, 2011), there is much to gain from amplified administrative and resource coordination with the federal government as the numbers of international students in Canada increase.

Federal immigration programs have been designed to include international students based on their integration advantage over traditional economic migrants. However, mismatches between policy intent and outcome highlight the need to apply employer responses to hiring international graduates in a meaningful and functional way, i.e. through employer engagement in international student skill development. It is recommended that provincial governments, in collaboration with the federal government where applicable, reach out to the private sector and provide incentives for employers to assist in building labour market readiness programs based on their knowledge of the challenges of employing immigrants.

\section{The Private Sector}

The development of cooperative relationships does not end with strengthening intragovernmental relations. As recommended in actions for the provincial governments, the private sector must be actively engaged in skill development programs for international students. By far the most significant barrier between 
policy intention and outcome, in respect to integration of immigrant labour into the Canadian economy, is the mismatch between immigration criteria and employer needs or demands. In the 2007 CBIE report Northern Lights: International Graduates of Canadian Institutions and the National Workforce, a small sample of 20 Canadian employers participated in a discussion on their perceptions of hiring international graduates. While the report fails to include quantitative data on how many employers did not have knowledge on employing international graduates, it was noted that "many" were unaware of their ability to do so, while "others" voiced concerns regarding the ability of international hires to travel for work. Employers' lack of immigration knowledge cannot be noted as the cause for international graduates inaccessibility to meaningful participation in the labour market from the CBIE (2007) report alone, due to the size of the sample. However because of the multitude of factors involved in successful policy outcomes and immigrant integration, it is probable that the employer-knowledge factor is but one element in a causal nexus of international student policy success-social inclusion. Further research on the dynamic between employers and international students is necessary to fully understand the impacts and effects of this relationship. Additional employer concerns on hiring foreign labour were voiced in the 2012 Employer Consultation Report (IEC BC, 2012). Amongst the most prevalent concerns were: English language proficiency, both general and occupation specific; the importance of Canadian experience; and the lack of a "one-stop" information site on hiring immigrants (IEC BC, 2012). While by no means a comprehensive list of employer-related concerns to hiring international graduates, those identified 
address the importance of employer engagement in federal policy relating to international students, specifically the PGWPP, the CEC and international student stream of the PNP. Additionally, employers should be encouraged to assume an active role in university co-operative education programs and career mentoring programs. The outcomes of these initiatives are almost certain to be mutually beneficial. Canadian employers are able to assess the capacity of international students to contribute to their respective sectors and thereafter, make informed recommendations to the federal government on economic immigration criteria. At the same time, international students gain Canadian experience - a key component of successful labour market integration for immigrants.

\section{The Post-Secondary Sector}

The importance of coordination between stakeholders is paramount in reconceptualization of international students in Canada under both the International Education Strategy and a social inclusion agenda. However, despite the amplified role of state actors, the private sector, and the third sector, i.e. settlement service providers, post-secondary institutions will remain the primary point of contact for international students. To date there is no national benchmarking system in place for international student services and as such support systems are in disarray at campuses coast-to-coast (see Table 2). This fragmentation is problematic. International students should not be expected to choose between a university with advanced English support programming and a university with well-developed connections to the private sector; the system should, 
and can, be streamlined and monitored though a federal designation system (see above Table 3). Kamara and Gambold's (2011) model that includes strategies they describe as "holistic and preemptive" (p. 25), offers insight into a service provision scheme that fosters social inclusion. Moving away from the current reactive approach to international student services requires the creation of a framework that takes a three-phase approach. This approach resonates with the aforementioned studies, providing awareness of the international student experience; from which themes of exclusion and even ghettoization have emerged (Cheng \& Fox, 2008; Liu, 2011).

Connecting post-secondary institutions with the resources and stakeholders to successfully host international students requires what Bakvis (2008) describes as entrepreneurial university presidents; leaders who have close connections to the private sector, the third, non-profit sector, and provincial and federal governments. The importance of this type of leadership at post-secondary institutions is vital. By liaising with key sectors of government and society, entrepreneurial university presidents are able to articulate the vision of their institution and lobby for support to facilitate shared goals of international education. Thus, it is recommended that post-secondary institutions include characteristics such as entrepreneurialism in the hiring criteria for university leaders.

\section{Resource Commitments}

Guided by neo-liberal ideology, one may question why the federal government would invest in international student inclusion at all. Past policy failures of 
economic immigration are central to the argument for increased funding and program development by the federal, and to some extent provincial governments. Critical examination of neo-liberal policy changes to the shift in prospective immigrant characteristics suggests that systemic issues in the immigration, settlement and integration processes for Canada's immigrants have been left unaddressed. Instead, policy changes imply past cohorts of immigrants unsuccessful, and encourage a new, 'improved' demographic of immigrant to Canada via the repositioning of the International Student Program and the Canadian Experience Class. Arguments advocating further download of services onto universities ignore such these barriers to full participation, and instead note postsecondary institutions as the primary benefactors of international students due to their immediate receipt of tuition fees. However, as international education becomes increasingly important to the Canadian economy, the federal government must look only to its close competitors in international higher education to imagine the consequences of strictly growth-oriented policies regarding international students. Australia has restructured its immigration points system, based on lack of foresight in respect to accepting increased numbers of international students into its PSE system without the necessary programs or services to facilitate integration or inclusion. The country's institutions, guided by federal policies, have graduated international students without refined language, social or labour market skills. Based on such skill underdevelopment, many of Australia's international graduates are unable to meaningfully engage with the labour market. This in turn has resulted in a system overhaul to ensure immigrant's skills match labour market needs, i.e. 
language, social capital or cultural/transition support. The costs associated with large modifications of the immigration system due to poor planning are far greater than the costs of funding programs to facilitate and manage the inclusion of international students in Canada.

At the provincial level, resource allocation can be as large or small as the province is capable of investing into engagement of the private sector for the purpose of maximizing the value of locally trained and workforce ready populations. Policy recommendations (see Table 3) for increased federal funding of international PSE have included safeguards for less economically well-to-do provinces. This is achieved by removing funding matching as a qualifier for higher education institutions to receive increased federal investment.

As explained throughout the description of the pathway approach, postsecondary institutions can adopt an inclusive programming agenda largely through engagement of existing employees and experienced international students. Additional support for new programs should be funded through increased federalprovincial transfers with the condition that resources be used to support initiatives of the International Education Strategy, as well as through the allocation of a portion of differential fees paid by international students. Further investment by the university is based on cost of hiring advisors for international students; depending on the ratio of students to advisors, this cost would vary.

In order for the proposed pathway approach to achieve success at the university level, increased funds by CIC are required to create and administer a predeparture orientation for international students, a valuable investment based on the 
2014 commitment in the International Education Strategy to strengthening the country's international education market. Strengthening means supporting, and for CIC this means resource allocation, and an active role in orienting international students on the opportunities and potential challenges of their migration journeys. Funding for an additional step in the institutional designation process must also be included. This is critical in assessing the strength of support received by international students at post-secondary institutions. It is this function of the pathway approach that is likely to receive the most pushback from higher education institutions; however, it is a necessary step in the comprehensive inclusion of international students in Canada. The potential tension in the implementation of a federal mechanism of evaluation for university support programs will likely be due to the current relationship between governments and post-secondary institutions. While it is beyond the scope of this analysis, this lack of cooperation is a matter that requires immediate attention, not just in relation to international student support, but as a core issue in the fragmentation the entire higher education sector in Canada.

\section{The Social Inclusion Perspective, Revisited}

All vulnerable populations are acknowledged in the guiding policies and mandates of universities Canada-wide. However, 1 social inclusion "... is proactive. It is about anti-discrimination. It is not about the passive protection of rights; rather it is about the active intervention to promote rights" (Saloojee, 2003, p. 15). Beginning with the university, the phased/pathway approach should be extended to include other important actors in the creation of successful outcomes of federal policy relating to 
the future roles of international students in the Canadian economy. The private sector must be engaged, informed and trained on how to include cultural competency into hiring practices. As it stands, immigrants to Canada are not being utilized to their full potential, resulting in disappointing outcomes for immigrants and governments alike. A plethora of federal policy shifts to maximize the economic capacities of immigrants to Canada can be written, but social inclusion through creation of social capital and systemic support mechanisms are the essential building blocks for generating positive experiences and successful policies.

Finally, the ethical dimension of encouraging international students to migrate permanently to Canada must be considered. Canadian federalism has resulted in a somewhat disconnected relationship in fulfilling the intentions of Canada's International Education Strategy. Provincial governments administer education, and immigration policy falls under the federal government (Bakvis \& Skogstad, 2008). Increasingly, however, non-governmental institutions have been delegated responsibilities traditionally assumed by the various levels of government, and so too have the obligations to ensure successful policy outcomes (Evans \& Shields, 2000). In the context of international students in Canada, responsibility for successful international student related policy outcomes have been passed to universities without their consent. The social inclusion perspective on the fulfillment of federal policy relating to international students, as applied in this analysis, has sought to engage international student populations as partners in their educations and migration intentions. The ethical dilemma of "brain drain" (Gates-Gasse, 2012, p. 290) is at the core of university-level underdevelopment of 
international student support services. This perspective views attempts to retain such students as potential immigrants as problematic due to the negative impacts of such retention on the economies of sending countries (Gribble, 2008). Thus, it sits in opposition to the neo-liberal race for talent that has guided federal policy. It is critical to the health of Canada's International Education Strategy, that the social inclusion of international students, and the contributions such populations are able to make in Canada and abroad that ideological conflicts are mediated and a compromise is reached. As per the recommendations offered above, mutual benefits can be experienced for all stakeholders of international education should social inclusion guide Canada's endeavours in international education.

This organizational structure of education in Canada has resulted in a lack of consensus on the intended goals and outcomes of international students in Canada. The pathway approach described above puts forth a framework by which collaborative international student support services can be established through multi-sectoral cooperation. Based on the current conflicts on the rationale for international students in Canada, mediated discussions between the governments, universities and the private sector must take place to clearly outline the benefits each actor has to gain is a critical starting point, and in turn their responsibilities and expectations. Programming to ensure advanced language skills to qualify for career employment in Canada or permanent residency pathways, as well as career mentorship to build social capital to succeed in Canada's competitive labour market are at present responsibilities to be assumed by university's student services. But the extent to which universities are solely responsible for creating the conditions 
necessary for successful policy outcomes, or to rectify the causes of exclusion caused by wider structural issues is highly debatable. After all, labour market struggles, language proficiency issues and accessing opportunities to build bridging social capital are not unique to international students; rather, they are common immigrant issues, Canada-wide (Lowe, 2011).

The pathway approach is a proactive model that has the potential to engage all relevant stakeholders in the social inclusion of international students, as well as in the fulfillment of federal policy intentions in respect to the populations' economic role. It has the possibility to promote policy success at all levels of government and in universities. However, it is by no means the only approach. Any inclusive approach first requires the federal government to examine its policies and consider what responsibilities are being handed to other levels of government or non-state actors. If the federal government is unsuccessful with its federal policies, then one of two things must happen. One, leave the policies as is or modify the policy so no other actors are required to ensure success. The first approach requires action through a bolstered network of institutions and other levels of government that provide the tools and resources for policy success. This may entail using a pathway, phase, or other multi-sectoral approach. The alternative involves modifying the policy so no additional actors are required to achieve success. The latter could mean that study permits assume similar points-system characteristics, whereby students are assessed in the same ways as economic applicants, while the former makes use of the capacities of stakeholders to develop the shape the skills of immigrants and promote their success. 


\section{Section VII}

\section{Conclusion}

The analysis in this paper has sought to assess the quality and quantity of programs and services for international students at Canadian universities. It is based on the current federal policies seeking to attract and retain international students as economic immigrants in the context of neo-liberalism and the global agenda of higher education. Contending that the extent to which programs provide international students with the tools necessary to integrate into academic, social, and professional life in Canada are not merely concerns for post-secondary institutions, the paper argues for a multi-stakeholder solution. The involvement of many different actors with strikingly distinct anticipated outcomes requires collaboration, cooperation and coordination to address the ways in which federal policy objectives have created the conditions for the international students' exclusion and to examine inclusive solutions.

With the political spotlight now on international students to successfully graduate from postsecondary institutions in Canada and seamlessly transition into the labour market and permanent residency, the need for international studentspecific programs and services is greater than ever. While the core challenges causing the failure of policies relating to international students are due in large part to the different jurisdictional responsibilities of international education and the resulting intragovernmental tensions, there is an immediate need for compromise. It is both unfair and unrealistic for universities to fund and administer all services international students require for full societal participation. The pathway approach 
provides one possible course of action available for international student stakeholders to create an inclusive, structured and intuitive service framework that also incorporates flexibility and individuality. Due to the long-standing engagement and frequent interaction with international student populations, post-secondary institutions have been recommended to continue administering the majority of support services.

Each stakeholder identified in this analysis has definite benefits, but in order to reap them investment is required. The real costs of modifying policies and implementing a pathway program varies, however it is certain that it will require increased transfers from the federal government to the provinces with the conditions that funds allocated to post-secondary institutions are directly applied to targeted international student support. The integration of a program evaluation function to work in tandem with CIC's designated institution process will ensure that there is standardization in the international student experience in Canada. This will work to fulfill the federal policy intentions of the International Student Program, as well as the PGWPP, CEC and PNP, all of which require that international students have refined labour market and language skills. For those students who do not wish to remain in Canada after graduation, the support received during their studies in Canada will ensure they are ambassadors to Canadian education in their home countries, or elsewhere, facilitating the ongoing expansion of the Canadian brand of international education.

The disagreement between governments and universities regarding which actor is the true benefactor of international students in Canada was highlighted 
throughout this analysis due to the enormous barrier the dispute has caused for the development of sustainable and effective programs for the social inclusion of international students. To that end, social inclusion was used as a measure for assessing the successes of federal policy, because of the perspective's identification of the multidimensional needs of individuals to thrive in society, as well as its action-oriented institutionally based method of dismantling barriers. Applying the social inclusion perspective has enhanced the understanding of the precise ways in which policy has caused a chain-reaction of exclusion for international students in the various institutions the population passes through, both as students and economic immigrants. The principles of social inclusion have not yet been applied in scholarly writing to the integration of temporary immigrant populations such as international students. Thus, the analysis provided in this paper offers not only suggestions for international student populations, but to other populations as well. Based on democratic citizenship and fostering community through collective action, the social inclusion perspective approaches policy, practice and lived experiences as interconnected phenomena. This paper has advanced the social inclusion perspective as a working model to assess exclusion for non-traditional societal groups, such as temporary migrants, and suggest multi-stakeholder solutions - an increasingly necessary strategy in the present political climate of austerity. To conclude this exploration of international students' social inclusion and the success of federal policy relating to the population, it is important to remember that there is no one method by which to realize a policy's goals. Rather, there are socially responsible ways that promote inclusion and participation, and there are 
top-down methods, which set hard to reach targets without adequate support, and too often, lead to disappointing outcomes. As Hawthorne (2011) cautions in her comparative assessment of the Australian and Canadian International Student Programs, "the lack of quality assurance could risk such students being 'treated as commodities in a marketplace that charges top dollar for low-grade education and training"' (Hawthorne, 2011, p. 55). While the key to creating the conditions for inclusion and successful policy outcomes are not straightforward, the deficiencies of the current approach are readily evident. Engaging all necessary stakeholders, defining responsibilities, and strengthening funding are the first steps toward achieving efficient and inclusive polices and practices for international students in Canada. 


\section{Appendix}

Program Scan of International Student Services at Canadian Universities

\section{University of British Columbia: International Student Services}

\begin{tabular}{|c|c|}
\hline $\begin{array}{l}\text { Language and } \\
\text { Culture }\end{array}$ & $\begin{array}{l}\text { - Academic English Support Program } \\
\text { - Tandem Language Program }\end{array}$ \\
\hline Academic & $\begin{array}{l}\text { - Academic English Support Program } \\
\text { - International Student Academic Advisor }\end{array}$ \\
\hline Financial & $\begin{array}{l}\text { - International Tuition Award } \\
\text { - } \text { Research and Teaching Assistantships } \\
\text { - UBC Graduate Support Initiative }\end{array}$ \\
\hline Inclusion & $\begin{array}{l}\text { - International House } \\
\text { - Access \& Diversity }\end{array}$ \\
\hline Labour Market & $\begin{array}{l}\text { - International Student Guide } \\
\text { - } \text { Regulated Canadian Immigration Consultant } \\
\text { - International Student Advisor }\end{array}$ \\
\hline
\end{tabular}

Description of Programs:

Access \& Diversity

- http://students.ubc.ca/about/access

- University-wide initiative to promote inclusivity, focusing on the following areas:
○ Race and ethnicity
- Sexual orientation and gender identity
○ Women
○ Disability
- Students who are parents
- Discrimination and harassment

- Students have access to Diversity Advisors, on campus or online

AES: Academic English Support Program 
- http://cstudies.ubc.ca/academic-english-support-program/

- One on one support to improve academic English skills for students who use English as an additional language

- Focuses on academic reading, writing, and note-taking based on individual needs

- Offers self-directed study through a student-language coach collaboratively created learning plan, using online resources such as self-study websites and short courses, one instructor-led course, and meetings with a language coach

- Requires a student commitment of 1-3 hours per week

- Open to all undergraduate and graduate level students with intakes throughout fall and winter semesters

Funding for International Graduate Students

- https://www.grad.ubc.ca/prospective-students/internationalstudents/funding-international-students

- International Tuition Award

○ https://www.grad.ubc.ca/prospective-students/internationalstudents/funding-international-students

- International graduate students automatically considered for up to $\$ 3200$ per annum, unless tuition is paid by a third-party agency

- Research and Teaching Assistantships

○ https://www.grad.ubc.ca/prospective-students/scholarshipsawards-funding/research-teaching-assistantships

- Part-time jobs under the supervision of a faculty member

- UBC Graduate Support Initiative

○ https://www.grad.ubc.ca/prospective-students/scholarshipsawards-funding

- Merit-based scholarships, stipends, and awards to financially assist international students

International House

- http://students.ubc.ca/international/about-us/services-at-i-house

- UBC's centre for international and intercultural learning; focus on international and domestic students, as well as staff, faculty, and community members as a site of knowledge sharing and growth

International Student Academic Advisor

- http://students.ubc.ca/success/student-supports/academicadvising/academic-advisors-international-students

- UBC undergraduate faculties have advisors who deal specifically with the academic concerns of international students; assist in course registration, choosing a major, relationships with professors, and other academic concerns 
International Student Advisor

- http://students.ubc.ca/about/isd\#advisor

- Specialized UBC advising staff dedicated to assisting international students

- Work in conjunction with RCIC

Regulated Canadian Immigration Consultants (RCIC)

- http://students.ubc.ca/about/isd

- Offer immigration advice for international students; services are limited students advised to seek private RCIC for further guidance

Tandem UBC Language Exchange Program

- http://www.tandemubc.ca

- Student-run English language conversation partners, using a two-way street model: each partner offers a language skill, focusing on a collaborative learning partnership

- Partnerships run for 1.5 hours for 10-11 weeks

- Participants are supported by lesson plans and suggested activities via the Tandem UBC Handbook, as well as by a team of trained volunteers 


\section{University of Calgary: International Student Services}

\begin{tabular}{|c|c|}
\hline $\begin{array}{l}\text { Language and } \\
\text { Culture }\end{array}$ & $\begin{array}{l}\text { - } \text { English for Academic Purposes } \\
\text { - } \quad \text { English Language Program } \\
\text { - } \text { International Student Advising }\end{array}$ \\
\hline Academic & - International Student Academic Advising \\
\hline Financial & - Scholarships/Awards \\
\hline Inclusion & $\begin{array}{l}\text { - Global Friendship Program } \\
\text { - } \text { Mentoring Program } \\
\text { - Orientation Program for International Students } \\
\text { Orion for First Year Graduate Students }\end{array}$ \\
\hline Labour Market & - International Student Advising \\
\hline
\end{tabular}

Description of Programs:

Centre for International Students and Study Abroad

- http://www.ucalgary.ca/uci/students/work

- Provides general advice for international students at UC and UC students studying abroad

- Does not offer immigration advice

English for Academic Purposes Program (EAP)

- http://www.ucalgary.ca/uci/students/english_language_programs

- In addition to offering prospective internationally educated students structured learning with English Language Proficiency requirements, the EAP offers seminars on scholarly writing and academic communications for admitted graduate students

English Language Program (ELP)

- http://www.ucalgary.ca/uci/students/english_language_programs

- Several program options for students who use English as an additional 
language to advance English proficiency: full-time, multi-course, intensive summer, customized group programs, part-time/evening writing and pronunciation, and part-time EP focused

Funding

- Scholarships/Awards

- http://grad.ucalgary.ca/awards

○ Externally funded, internally administered only

Global Friendship Program

- http://www.ucalgary.ca/uci/involved/programs

- Collaborative program promoting friendship between international and Canadian students; facilitates twice monthly meetings for student connections in the Calgary area focusing on Canadian culture and crosscultural sharing

International Student Academic Advising

- http://www.ucalgary.ca/uci/students/internationalstudentacademic

- Providing support for undergraduate and graduate international students

- Focus on: time management strategies, academic language development, reading and writing skills, and transitioning into academic life in Canada

- Offers workshops on developing academic skills in a second language (reading, writing, vocabulary, and revision)

International Student Advising

- http://www.ucalgary.ca/uci/students/internationalstudentadvising

- International Student Advisors provide non-academic information on the following:

- Social Insurance Numbers (SIN)

○ Banking

- Health Insurance and the Canadian medical system

- Transition to Canada (cultural and personal)

- International student programs (Global Friendship Program, International Mentorship Program)

Language Bank

- http://www.ucalgary.ca/uci/involved/programs

- Provides opportunities for students to connect and learn languages, using a two-way street model; each student teaches the other a language; incorporates opportunities to attend cultural events in the languages being learned

Mentoring Program

- http://www.ucalgary.ca/uci/involved

- UC students are matched with new international students to assist in the 
transition

Orientation for First Year Graduate Students

- http://grad.ucalgary.ca/current/newly-admitted/graduate-orientation

- Organized for the wider graduate student body with international student specific seminars (general information, scholarships/funding)

Orientation Program for International Students

- http://www.ucalgary.ca/uci/students/orientationprogram

- Introduction to UC and Calgary for all new international students, undergraduate and graduate; topics include using UC libraries/resources, filing taxes, Calgary services, banking, health insurance/services, student

Ryerson University: International Student Services

\begin{tabular}{|c|c|}
\hline $\begin{array}{l}\text { Language and } \\
\text { Culture }\end{array}$ & $\begin{array}{l}\text { - } \text { English Language Support } \\
\text { - } \quad \text { ESL/EAL Certificate } \\
\text { - } \quad \text { Tri-Mentorship Program }\end{array}$ \\
\hline Academic & $\begin{array}{l}\text { - English Language Support } \\
\text { - ESL/EAL Certificate }\end{array}$ \\
\hline Financial & $\begin{array}{l}\text { - International Student Advising } \\
\text { - Internal Scholarships (RGS, RGA) } \\
\text { - RA or GA employment } \\
\text { - Graduate stipend }\end{array}$ \\
\hline Inclusion & $\begin{array}{l}\text { - International Student Orientation } \\
\text { - Tri-Mentorship Program }\end{array}$ \\
\hline Labour Market & $\begin{array}{l}\text { - International Student Advising } \\
\text { - } \quad \text { Career Mentorship Program }\end{array}$ \\
\hline
\end{tabular}

Description of Programs:

English Language Support

- http://www.ryerson.ca/studentservices/els/ 
- Provides RU students who use English as an additional language English language services and no-credit programs, ensuring that multilingual students successfully transition into university in English

- Services offered:

- Paper Partners Program: individual help with written assignments (also available online)

- English Communication Support: practical non-credit classes focusing on academic speaking skills

- Conversation Circle: group discussions structured around oral fluency and interpersonal communication skills

- Conversation Partners Program: one-on-one support catering to improving English conversation and pronunciation

- Conversational Connections Program: promotes cultural exchange through a partnership program with The Chang School of Continuing Education's Programs for 50+

- Language Labs: available online and in-person; three labs structured around listening skills, reading skills, and pronunciation

- Presentation Skills Laboratory: individual sessions structured around improving presentation skills and receiving feedback for further improvement

- Online Academic Writing Modules: targeted at students who prefer self-study; focus on overcoming writing challenges

- Graduate Studies: available for students requiring assistance with theses and dissertations, grant applications, and research reports

ESL/EAL Certificate Program:

- http://ce-online.ryerson.ca/ce/default.aspx?id=3111

- Provides a flexible curriculum for ESL/EAL students, aimed at individuals who are preparing for entry to postsecondary education or to advance their careers; offers in-class, hybrid, or online modes of courses at the intermediate or advanced level; students may take individual courses without enrolling in the certificate program

Funding:

- http://www.ryerson.ca/ comrel/graduate/funding/

- Due to CIC study permit regulations, international students are required to demonstrate financial resources; should RU provide an offer of admission with financial support, international students must submit a letter of understanding that RU is not obliged to provide further financial support than outlined in the admission offer

- Types of funding for international students:

○ Internal:

- Ryerson Graduate Scholarship (RGS): \$7000; based on academic excellence

- Ryerson Graduate Award (RGA): based on academic merit, 
provided by individual programs less than the amount of an RGS

- Graduate Stipend: paid from research funding of faculty supervisors; when only source of funding must be $\$ 1000 /$ month or $\$ 12,000 /$ year

- Research Assistantships: employment available to graduate students assisting Principal Investigators in research not related to students' studies; minimum rates of pay recommended by CUPE 3 Collective Agreement

- Graduate (Teaching) Assistants: employment available to graduate students to assist with teaching or related duties, up to 10 hours per week; rate of pay outlined in CUPE 3 Collective Agreement

○ Externally funded, internally administered scholarships; merit based, amount varies

International Peer Support Program:

- http://www.ryerson.ca/internationalservices/newarrivals/peersupport.htm l

- International students and International Peer Supporter are paired based on commonalities academically and culturally; mentorships are intended to bridge new international students with RU and Canada, and promote involvement in RU's International Student Services events and workshops

International Student Advising:

- http://www.ryerson.ca/internationalservices/services/immigration/advisin g.html

- Offers advising on: immigration related questions, such as Study and Work Permits; health insurance; financial assistance; ISS Work Experience Program; Volunteering;

○ Funding: focus on options available only to international students, however has an undergraduate focus; for graduate students only Ryerson International Student Scholarships (automatic consideration) and BMO Financial Group Diversity Scholarships

International Student Orientation

- http://www.ryerson.ca/internationalservices/newarrivals/orientation.html

- Introduction to RU, ISS, offers specialized workshops, and events throughout the year

- Graduate International Student Orientation Workshop: covers topics specific to graduate IS such as finding TA/RA positions, obtaining a SIN, UHIP, and immigration related issues

Tri-Mentoring Program

- http://www.ryerson.ca/studentservices/trimentoring/index.html 
- A student mentorship program designed to enhance the academic, personal, and employment success of RU students, with a focus on culturally and linguistically diverse students and their transitions into RU life and into career-related employment post-graduation; available to all students

- Career Mentoring:

○ http://www.ryerson.ca/studentservices/trimentoring/careermentori ng/index.html

- A sub-program that offers culturally sensitive and constructive feedback through mentorship to students in their final year of study to assist in preparation for labour market entry; available to all students

\section{Memorial University: International Student Services}

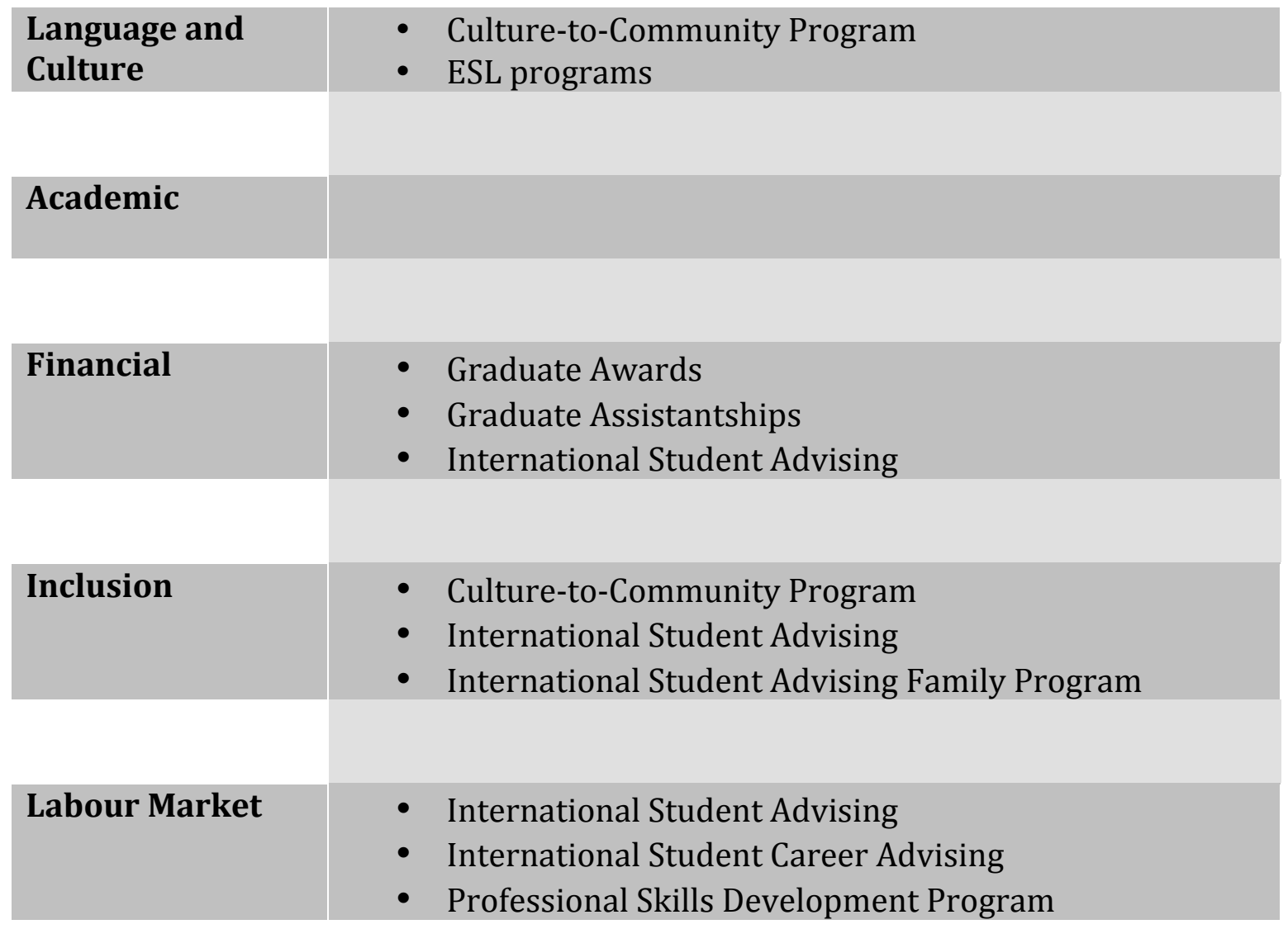

Description of Programs:

Culture-to-Community Program

- http://www.mun.ca/isa/culture2community/memorial-students.php

- An educational outreach program that links the NL K-12 school system with 
international and new immigrant students at MUN; aims to increase intercultural understanding and respect for cultural difference

English as a Second Language Programs

- http://www.mun.ca/esl/about/

- Custom Designed Courses

○ Program-specific ESL courses for groups (e.g. healthcare, business, etc.)

- 5 Week English Language Summer School

- Intensive ESL immersion program for students 19+, with proficiency levels from low-intermediate to advanced; covers reading, writing, listening, and speaking skills

- 12 Week Intensive English Program

- Multi-skill ESL program for students who are preparing for full-time university in English or who are furthering their English for professional purposes; designed for students at the low-intermediate to advanced proficiency levels

- Conversation Partner Program

- Designed to focus on both language and culture, pairing international students with domestic or native English speaking students

- Professional English Program

- ESL program focusing on development of communication and soft skills necessary for success in Canadian labour market; communications courses address specific language needs of professionals and cultural language competency; designed for advanced level ESL learners

Funding:

- http://www.mun.ca/sgs/current/scholarships/awards.php

- Graduate Awards

- International graduate students are eligible for a number of external scholarships, administered internally - amounts and conditions vary

- Graduate Assistantships

○ http://www.mun.ca/sgs/current/Graduate_Assistantships.php

$\circ \quad$ Open to all full-time graduate students; hiring carried out by individual departments

International Student Advising:

- $\quad$ http://www.mun.ca/isa/index.php

- Offers international students advice on health insurance, academic and career paths, and settlement support

- Offer periodic sessions/workshops with certified Immigration Consultants

International Student Advising Family Program:

- $\quad$ http://www.mun.ca/isa/family/ 
- Welcoming international students families on campus and in Canada by offering information on family health care, schools and daycares for children, family tax benefits, employment/volunteer opportunities for spouses, language classes available for spouses, local resources, and parenting resources

International Student Career Advisor:

- http://www.mun.ca/isa/main/career.php

- Offers international students advice on how to create and improve cover letters and resumes, search for jobs on or off campus, search for career employment post-graduation, interview preparation

International Student Checklist

- http://www.mun.ca/isa/new/

- Online checklists to assist international students through the MUN application process, pre-arrival process, and post-arrival/settlement process

MUN Mentors Program

- http://www.mun.ca/isa/mun_mentors/

- Peer mentorship program for international students, creating bonds between domestic and international MUN students, offer international students opportunities to learn about Canadian culture, and learn how to be successful in university and the city

Professional Skills Development Program (PSDP)

- http://www.mun.ca/isa/employment/psdp.php

- A program developed for undergraduate and graduate international students who wish to remain in NL or Canada post-graduation; weekly sessions covering topics such as communication, culture, voluntary work, and professional skill development 


\section{References}

Aizlewood, A. \& Pendakur, R. (2004). Ethnicity and Social Capital in Canada.

Research on Immigration and Integration in the Metropolis, Working Paper Series, No. 04-09.

Albiom, N. (2011). From International Student to Permanent Resident. Canadian Diversity, Winter, 8(5): 15-19.

Anisef, P., Sweet, R., \& Adamuti-Trache, M. (2010). Impact of Canadian Postsecondary Education on Recent Immigrants' Labour Market Outcomes. Retrieved from http://www.cic.gc.ca/english/resources/research/impact_postsecondary.as $\mathrm{p}$

Arat-Koc, S. (1999). Neoliberalism, State Restructuring and Immigration: Changes in Canadian Policies in the 1990s. Journal of Canadian Studies 34(2), 31-56.

Association of Universities and Colleges of Canada (AUCC). (2007). Canadian universities and international student mobility fact sheet. Retrieved from http://www.aucc.ca/wp-content/uploads/2011/05/student-mobility2007.pdf

Association of Universities and Colleges of Canada (AUCC). (2011). Trends in Higher Education - enrolment. Retrieved from http://www.aucc.ca/wpcontent/uploads/2011/05/trends-2011-vol1-enrolment-e.pdf

Arthur, N. \& Achenbach, K. (2002). Developing multicultural counseling competencies through experiential learning. Counselor Education and Supervision, 42(1), 2-14.

Arthur, N. \& Flynn, S. (2011). Career development influences of international 
students who pursue permanent immigration to Canada. International Journal for Educational and Vocational Guidance, 11(3), 221-237.

Arthur, N. \& Popadiuk, N. (2010). A Cultural Formulation Approach to Career Counseling with International Students. Journal of Career Development, 37(1), 423-440.

Baglay, S. (2012). Provincial Nominee Programs: A Note on Policy Implications and Future Research Needs. International Migration \& Integration, 13, 121-141.

Bakvis, H. (2008). The Knowledge Economy and Post-Secondary Education: Federalism in Search of a Metaphor. In H. Bakvis \& G. Skogstad (Eds.) Canadian Federalism: Performance, Effectiveness, and Legitimacy (205-222). Don Mills, ON: Oxford University Press.

Bakvis, H. \& Skogstad, G. (2008). Canadian Federalism: Performance, Effectiveness, and Legitimacy. In H. Bakvis \& G. Skogstad (Eds.) Canadian Federalism: Performance, Effectiveness, and Legitimacy (3-22). Don Mills, ON: Oxford University Press.

Banting, K. (2006). Dis-embedding Liberalism? The New Social Policy Paradigm in Canada. In D. Green \& R. Kesselman (Eds.) Dimensions of Social Inequality in Canada, 417-452. Vancouver, BC: UBC Press.

Bauder, H. (2008). The Economic Case for Immigration: Neoliberal and Regulatory Paradigms in Canada's Press. Studies in Political Economy, 82, 131-152.

Benick, G. \& Saloojee, A. (1996). Creating Inclusive Post-Secondary Learning Environments. The Post-Secondary Anti-Harassment and Discrimination Project, Ryerson University. 
Benzie, H.J. (2010). Graduating as a 'native speaker': international students and English language proficiency in higher education. Higher Education Research \& Development, 29(4), 447-459.

Berman, R. \& Cheng, L. (2001). English academic language skills: Perceived difficulties by undergraduate and graduate students, and their academic achievement. Canadian Journal of Applied Linguistics, 4(1-2), 25-40.

Bishop, A. (2005). Beyond Token Change: Breaking the Cycle of Oppression in Institutions. Blackpoint, Nova Scotia: Fernwood Publishing.

Bucklaschuk, J. \& Wilkinson, L. (2011). A Profile of Economic and Labour Market Integration among Immigrants in Canada. Edmonton, AB: Prairie Metropolis Centre. Retrieved from http://www.ualberta.ca/ pcerii/final\%20reports/RDC\%20review\%20pape r\%20FINAL\%20July\%2015\%5B1\%5D.pdf

Canadian Bureau for International Education (CBIE). (2013). A World of Learning: Canada's Performance and Potential in International Education.

Canadian Bureau for International Education (CBIE). (2012). Facts and Figures: Canada's performance in international education, 2012. Retrieved from http://www.cbie.ca/about-ie/facts-and-figures/

Canadian Bureau for International Education (CBIE). (2009). Canada First: The 2009 Survey of International Students.

Canadian Bureau for International Education (CBIE). (2007). Northern Lights: International Graduates of Canadian Institutions and the National Workforce. Canadian Federation of Students. (2013). Funding for Post-Secondary Education. 
Retrieved from http://cfs-fcee.ca/wp-

content/uploads/sites/2/2013/11/Fact-Sheet-Funding-2013-11-En.pdf

Cappon, P. (2014). Thank Nationally, Act Locally: A pan-Canadian strategy for education and training. Canadian Council of Chief Executives: Taking Action for Canada - Jobs and Skills for the $21^{\text {st }}$ Century. Retrieved from http://www.ceocouncil.ca/wp-content/uploads/2014/07/Paul-CapponThink-nationally-act-locally-July-4.pdf

Castles, S. (2004). The Factors that Make and Unmake Migration Policies. International Migration Review, 38(3), 852-884.

Chen, L. (2008). Internationalization or international marketing?: Two frameworks for understanding international students' choice of Canadian universities. Journal of Marketing for Higher Education, 18(1), 1-33.

Cheng, L. \& Fox, J. (2008). Towards a Better Understanding of Academic Acculturation: Second Language Students in Canadian Universities. The Canadian Modern Language Review, 68(2), 307-333.

Cheng, L. Myles, J., \& Curtis, A. (2004). Targeting language support for non-native English-speaking graduate students at a Canadian university. TESL Canada Journal, 21(2), 50-71.

Chira, S. (2009). From Internationalizing Atlantic University Campuses to Internationalizing Halifax, Nova Scotia? Commissioned by the Association of Atlantic Universities and the Atlantic Metropolis Centre.

Citizenship and Immigration Canada (CIC). (2014). Canadian Experience Class. Retrieved from http://www.cic.gc.ca/EnGLish/immigrate/cec/index.asp 
Citizenship and Immigration Canada (CIC). (2013a). Facts and Figures 2012 Immigration overview: Permanent and temporary residents. Retrieved from http://www.cic.gc.ca/EnGLish/resources/statistics/facts2012/temporary/1 3.asp

Citizenship and Immigration Canada (CIC). (2013b). Provincial Nominees. Retrieved from http://www.cic.gc.ca/enGlIsh/immigrate/provincial/index.asp

Citizenship and Immigration Canada (CIC). (2012). Evaluation of the Overseas Orientation Initiatives. Research and Evaluation. Retrieved from http://www.cic.gc.ca/english/resources/evaluation/ooi/introduction.asp

Citizenship and Immigration Canada (CIC). (2010). Evaluation of the International Student Program. Research and Evaluation. Retrieved from http://www.cic.gc.ca/english/pdf/research-stats/2010-eval-isp-e.pdf

Daller, M. \& Phelan, D. (2013). Predicting International Student Study Success. Applied Linguistics Review, 4(1), 173-193.

Dib, K. (2006). Multiculturalism and Diversity: Vehicles for Sustainable SocioEconomic Progress. Canadian Ethnic Studies, 38(3), 143-158.

Dunn, W. \& Oliver, C. (2011). Creating Welcoming and Inclusive University Communities. Canadian Diversity, 8(5), 35-38.

Evans, B.M. \& Shields, J. (2000). Neo-liberal restructuring and the Third Sector: Reshaping Governance, Civil Society, and Local Relations. Toronto: Centre for Voluntary Sector Studies, Ryerson University, Working Paper \#13.

Fama, M. (2011) A New Era for Canada's International Student Program. Canadian Diversity, 8(5), 11-14. 
Foster, J. (2012). Making Temporary Permanent: The Silent Transformation of the Temporary Foreign Worker Program. Just Labour: A Canadian Journal of Work and Society, 19, 22-45.

Gates-Gasse, E. (2010). “Two-Step” Immigration: Canada’s new immigration system raises troubling issues. Retrieved from https://www.policyalternatives.ca/publications/monitor/two-stepimmigration

Gates-Gasse, E. (2012). International Students as Immigrants. In H. Bauder (Ed.) Immigration and Settlement: Challenges, Experiences, and Opportunities (271295. Canadian Scholars' Press Inc.: Toronto, ON.

Govt. Canada. (2014a). Canada's International Education Strategy. Retrieved from http://international.gc.ca/global-markets-marchesmondiaux/assets/pdfs/overview-apercu-eng.pdf

Govt. Canada. (2014b). Changes to the International Student Program. Retrieved from http://www.cic.gc.ca/english/study/study-changes.asp

GOVision. (2014). The Impact of Changes to the CEC Program on International Student. Ryerson Centre for Immigration and Settlement, Working Paper No. 2014/15. Retrieved from http://www.ryerson.ca/content/dam/rcis/documents/RCIS_WP_GOVision_2 014_5.pdf

Gribble, C. (2008). Policy options for managing international student migration: the sending country's perspective. Journal of Higher Education Policy and Management, 30(1), 25-39 
Guo, S. \& Chase, M. (2011). Internationalization of higher education: integrating international students into Canadian academic environment. Teaching in Higher Education, 16(3), 305-318.

Guo, S. \& Jamal, Z. (2007). Cultural Diversity and Inclusive Teaching. London, ON: Society for Teaching and Learning in Higher Education.

Guruz, K, (2011). Higher Education and International Student Mobility in the Global Knowledge Economy. International Student Mobility: Other Major and Emerging Host Countries - Canada (275-280). Albany, NY: State University of New York Press.

Hawthorne, L. (2011). Australia's Experiment with Two-Step Migration. Canadian Diversity, 8(5), 50-58.

Hendrickson, B., Rosen, D., \& Kelly Aune, R. (2011). An analysis of friendship networks, social connectedness, homesickness, and satisfaction levels of international students. International Journal of Intercultural Relations, 35, 281-295.

Hill, D. \& Kumar, R. (2009). Global Neoliberalism and Education and its Consequences. NY, NY: Routledge.

Hire Immigrants Ottawa. (2012). Ottawa's Underutilized Immigrant Workforce. Retrieved from http://www.hireimmigrantsottawa.ca/wpcontent/uploads/2013/10/Underutilized_EN_2012.pdf

Immigrant Employment Council of British Columbia (IEC BC). (2012). BC Employer Consultation Report: Recruiting and Retaining Immigrant Talent. Retrieved from http://iecbc.ca/sites/default/files/IEC- 
BC_BCEmployerConsultationReport_Spring2012.pdf

Kamara, A. \& Gambold, L. (2011). Immigration and Diversity: Exploring Challenges Facing International Students On and Off Campus. Canadian Diversity, 8(5), 25-29.

Kelley, N. \& Trebilcock, M. (2010). The Making of the Mosaic: A History of Canadian Immigration Policy, $2^{\text {nd }}$ Edition. Toronto, ON: University of Toronto Press.

Kelly, N. T. (2012). International Students As Immigrants: Transition Challenges And Strengths Of Current And Former Students. ProQuest Theses and Dissertations, Paper 1496.

Kenyon, K., Frohard-Dourlent, H., \& Roth, W. (2012). Falling between the cracks: Ambiguities of international student status in Canada. The Canadian Journal of Higher Education, 42(1), 1-24.

Knutson, S. (2011). Post-Secondary Programs, Policies, and Partnerships: The Case of International Students at Memorial University of Newfoundland. Canadian Diversity, 8(5), 43-45.

Leask, B. \& Carroll, J. (2011). Moving beyond 'wishing and hoping': internationalisation and student experiences of inclusion and engagement. Higher Education Research \& Development, 30(5), 647-659.

Liu, L. (2011). An International Graduate Student's ESL Experience Beyond the Classroom. TESL Canada Journal, 29(1), 77-92.

Lowe, S. (2011). Welcome to Canada? Immigration Incentives may not be Enough for International Students to Stay. Canadian Diversity, 8(5), 20-24.

McGrath, C. (2010). Services for Diverse Students. In D. Hardy Cox \& C. Carney Stone 
(Eds.) Achieving Student Success (153-164). Montreal, QC: McGill-Queens University Press.

Meekison, J.P. (2011). Post-Secondary Education: An Intergovernmental Anomaly. Retrieved from http://web.uvic.ca/jmc/events/sep2011-aug2012/2011-10modes-of-gov/papers/2011-Modes_of_Gov-Panel_DJ_\%20Peter_Meekison.pdf

Mendelsohn, D. (2002). The lecture buddy project: An experiment in EAL listening comprehension. TESL Canada Journal, 20(1), 64-73.

Mitacs. (2012). Globalink. Retrieved from http://www.mitacs.ca/globalink Mirwaldt, P. (2010). Health and Wellness Services. In D. Hardy Cox \& C. Carney Stone (Eds.) Achieving Student Success (124-140). Montreal, QC: McGillQueens University Press.

Moores, L. \& Popadiuk, N. (2011). Positive Aspects of International Student Transitions: A Qualitative Inquiry. Journal of College Students Development, 52(2), 291-306.

Myles, J. \& Cheng, L. (2003). The social and cultural life of non-native English speaking international graduate students at a Canadian university. Journal of English for Academic Purposes, 2, 247-263.

Nakache , D. and P. Kinoshita. (2010). The Canadian Temporary Foreign Worker Program: Do Short-Term Economic Needs Prevail over Human Rights Concerns? IRPP Study, No. 5. Retrieved from http://oppenheimer.mcgill.ca/The-Canadian-Temporary-Foreign 
Nunes, S. \& Arthur, N. (2013). International students' experiences of integrating into the workforce. Journal of Employment Counseling, 50(1), 34-45.

Ogbuagu, B. \& Ogbuagu, C. (2013). Who Says We are Dumb?: Identification of the Causes of Learning Difficulties Encountered by New Immigrant Learners in their Adaptation to the Canadian Classrooms. Journal of Educational and Social Research, 3(2), 75-95.

Organisation for Economic Co-Operation and Development (OECD). (2004). Internationalisation and Trade in Higher Education: Opportunities and Challenges. Centre for Educational Research and Innovation. Retrieved from http://www.oecd-ilibrary.org/education/internationalisation-and-trade-inhigher-education_9789264015067-en

Papademetriou, D. G. (2014). Migration's Local Dividends: How Cities and Regions Can Make the Most of Immigration. The $11^{\text {th }}$ Plenary Meeting of the Transatlantic Council on Migration, Council Statement.

Pendakur, R. \& Mata, F. (2012). Social Capital Formation and Diversity: Impacts of Individual and Place-Related Characteristics. Journal of Ethnic and Migration Studies, 38(10).

Peykov, P. (2004). Immigrant Skilled Workers. Should Canada be Attracting More Foreign Students? Saskatchewan Institute of Public Policy. Retrieved from www.worldcat.org/oclc/246912935.

Popaduik, N. \& Arthur, N. (2004). Counseling international students in Canadian schools. International Journal for the Advancement of Counseling, 26(2), 125- 
145.

Putnam, R. (2006). E Pluribus Unim: Diversity and Community in the Twenty-First Century. Nordic Political Science Association.

Rai, V. (2013). Labour Market Information for Employers and Economic Immigrants in Canada: A Country Study. Centre for the Study of Living Standards, Research Report, 2013-01. Retrieved from http://www.csls.ca/reports/csls2013-01.pdf

Ranta, L., \& Meckelborg, A. (2013). How much exposure to English do international graduate students really get? Measuring language use in a naturalistic setting. Canadian Modern Language Review, 69(1), 1-33.

Roach, E. (2011). Service Needs and Gaps for International Students Transitioning to Permanent Residency in a "Two-Step" Immigration Process: A Toronto-Based Study. Unpublished.

Roslyn Kunin \& Associates Inc. (2012). Economic Impact of International Education in Canada - An Update: Final Report. Retrieved from http://www.international.gc.ca/education/assets/pdfs/RKA_IntEd_Report_e ng.pdf

Saloojee, A. (2003). Social Inclusion, Anti Racism and Democratic Citizenship. Laidlaw Foundation: Perspectives on Social Inclusion, Working Paper Series. Retrieved http://laidlawfdn.org/library/laidlaw-publications/workingpaper-series-on-social-inclusion/

Sawir, E. Marginson, S, Forbes-Mewett, H., Nyland, C. \& Ramia, G. (2012). International Student Security and English Language Proficiency. Journal of 
Studies in International Education.

Shachar, A. (2006). The Race for Talent: Highly Skilled Migrants and Competitive Immigration Schemes. University of Toronto Legal Studies Series, Research Paper No. 883739. Toronto, ON: University of Toronto, Faculty of Law.

Shanahan, T. \& Jones, G. (2007). Shifting roles and approaches: government coordination of post-secondary education in Canada, 1995-2006. Higher Education Research \& Development, 26(1), 31-43.

Siemiatycki, M. \& Triadfilopoulos, T. (2010). International perspectives on immigrant service provision. Mowat Centre for Policy Innovation. Toronto, ON: University of Toronto.

Simon, B. (2014). Canada's International Education Strategy: time for a fresh curriculum. Canadian Council for Chief Executives: Taking Action for Canada - Jobs and Skills. Retrieved from http://www.ceocouncil.ca/wpcontent/uploads/2014/06/Bernard-Simon-Canadas-InternationalEducation-Strategy-FINAL.pdf

Snow Andrade, M. (2006). International students in English-speaking universities: Adjustment factors. Journal of Research in International Education, 5(2), 131154.

Statistics Canada. (2011). A Changing Portrait of International Students in Canadian Universities. Retrieved from http://www.statcan.gc.ca/pub/81-004x/2010006/article/11405-eng.htm

Sweetman, A. \& Warman, C. (2010). A New Source of Immigration: The Canadian Experience Class. Policy Options, July-August 2010, 58-61. 
Vineberg, R. (2014). Immigrant Settlement Program needs an overhaul. CanadaWest Foundation. Retrieved from http://cwf.ca/commentaries/immigrantsettlement-program-needs-an-overhaul

Wade, M. \& Belkhodja, C. (2011). Managing a New Diversity on a Small Campus. Canadian Diversity, Winter, 8(5), 39-42.

Walsh, J, (2008). Navigating Globalization: Immigration Policy in Canada and Australia, 1945-2007. Sociological Forum, 23(4), 786-812.

Walton-Roberts, M. (2011). Immigration, the university and the welcoming second tier city. Journal of International Migration and Integration, 12(4), 453-473.

Waters, J. (2006). Emergent Geographies of International Education and Social Exclusion. Antipode, 38(5), 1046-1068.

Yang, R. P., Noels, K. A. \& Saumure, K. D. (2006). Multiple routes to cross-cultural adaptation for international students: Mapping the paths between selfconstruals, English language confidence, and adjustment. International Journal of Intercultural Relations, 30(4), 487-506.

Zheng, J. (2010). Neoliberal Globalization, Higher Education Policies and International Student Flows: An Exploratory Case Study of Chinese Graduate Student Flows to Canada. Journal of Alternative Perspectives in the Social Sciences, 2(1), 216-244. 
